\title{
HEGEMONIA \\ ROMANA E \\ TRANSFORMAÇÕES \\ CULTURAIS NO \\ MEDITERRÂNEO \\ (SÉCULOS IV-II A. C.): \\ NOVAS PERSPECTIVAS \\ DA HISTÓRIA GLOBAL
}

Contato

Av. Pres. Antônio Carlos, 6627

31270-901 - Belo Horizonte - Minas Gerais rscopacasa@ufmg.br
- Rafael Scopacasa*

Universidade Federal de Minas Gerais

Belo Horizonte - Minas Gerais - Brasil

\section{Resumo}

Este artigo discute a utilidade da história global para o estudo do Mediterrâneo durante a expansão romana inicial (séculos IV a II a. C.). No contexto cada vez mais interligado e dinâmico do Mediterrâneo romano, trocas e influências culturais ocorriam a partir de diferentes pontos, em vários sentidos, gerando diversos resultados. Tais dinâmicas serão aqui exploradas a partir de estudos de casos da Itália e do mundo grego, através da análise combinada de fontes históricas e materiais. Serão examinados os efeitos da conectividade crescente (ou "glocalização") em diferentes camadas sociais (elites e não elites), em vista de mudanças nas práticas sociais de culto, consumo e ostentação.

\section{Palavras-chave}

Globalização - história global - romanização - Itália - consumo - ex-votos anatômicos.

* Doutor em História Antiga pela University of Exeter e professor adjunto de História Antiga no Departamento de História da Universidade Federal de Minas Gerais. 


\section{ROMAN HEGEMONY \\ AND CULTURAL}

CHANGE IN THE

MEDITERRANEAN,

THIRD-SECOND

CENTURIES BC: NEW

PERSPECTIVES FROM

GLOBAL HISTORY

Contact

Av. Pres. Antônio Carlos, 6627

$31270-901$ - Belo Horizonte - Minas Gerais rscopacasa@ufmg.br
- Rafael Scopacasa

Universidade Federal de Minas Gerais

Belo Horizonte - Minas Gerais - Brazil

\section{Abstract}

This article discusses the utility of global history for the study of cultural change in the Mediterranean during the early Roman expansion (fourth-second centuries BC). By combining historical and archaeological evidence from Italy and the Greek world, this article traces increased connectivity and its diverse effects across the social transect (elites and non-elites) in view of patterns in worship,

\section{Keywords} consumption and display.

Romanization - Italy - consumption - pottery - anatomical votives. 


\section{Introdução}

O conceito de globalização é um produto do mundo contemporâneo: o termo descreve transformações econômicas, políticas, culturais e ambientais do presente. A globalização, tal como a vivenciamos hoje, envolve a formação de um mercado mundial com preços unificados, assim como meios de comunicação e de transporte ultra velozes, que causam a compressão do espaço-tempo e possibilitam a mobilidade de pessoas, mercadorias e ideias em uma escala nunca antes vista. ${ }^{1}$ Contudo, já nos anos 1990, estudiosos debatiam se a globalização seria um fenômeno unicamente moderno. Por um lado, Roland Robertson, Anthony Giddens e John Tomlinson definiam a globalização como um processo específico ao mundo contemporâneo e sem precedentes na história. ${ }^{2}$ Já Malcolm Waters e Arjun Appadurai mantinham um entendimento mais relativo: para eles, a principal característica da globalização seria a menor importância de barreiras geográficas e distâncias físicas na formação de contatos culturais, econômicos, políticos e sociais. ${ }^{3}$ Atualmente, muitos estudiosos acreditam que é possível identificar processos de globalização em sociedades pré-modernas, em vista de fenômenos como o encurtamento relativo das distâncias (através de meios de transporte e comunicação mais eficazes), maior conectividade entre regiões previamente isoladas, a formação de uma consciência global, ${ }^{4}$ e a convergência de preços e mercados entre regiões distantes.

O estudo da globalização como um fenômeno recorrente na história tornou-se mais complexo com o desenvolvimento da história global. ${ }^{5}$ Ao

\footnotetext{
1 Cf. HARVEY, David. The condition of postmodernity. Oxford: Blackwell, 1989; ROBERTSON, Roland. Globalization. Social theory and global culture. Londres: Sage, 1992; APPADURAI, Arjun. Grassroots globalization and the research imagination. In: Idem (org.). Globalization. Durham: Duke University Press, 2001, p. 1-21.

2 TOMLINSON, John. Globalization and culture. Cambridge: Polity Press, 1999, p. 2; ROBERTSON, Roland, op. cit., p. 8; GIDDENS, Anthony. The consequences of modernity. Stanford: Stanford University Press, 1990, p. 64.

3 WATERS, Malcolm. Globalization. Londres: Routledge, 2001, p. 5; APPADURAI, Arjun, op. cit., p. 6. Por esse ponto de vista, é possível usar o conceito de globalização para examinar contextos pré-modernos onde ocorre a intensificação de conectividade, tendo em mente a grande diferença de escala entre globalizações antigas e a contemporânea.

${ }^{4}$ HARVEY, David, op. cit.

${ }_{5}$ CONRAD, Sebastian. What is global history? Princeton: Princeton University Press, 2016, p. 5; BELICH, James; DARWIN, John; WICKHAM, Christopher. Introduction. In: BELICH, James; DARWIN, John; FRENZ, Margret; WICKHAM, Christopher (org.). The prospect of global history. Oxford: Oxford University Press, 2016, p. 3-22; CROSSLEY, Pamela. What is global history. Cambridge:
} 
invés de almejar uma história total do mundo, a história global propõe uma abordagem centrada não em recortes geográficos definidos (regiões ou países), mas nas conexões que atravessam longas distâncias e barreiras políticas, privilegiando temas como conectividade, mobilidade, migração, comércio e colonização. A história global reconhece diferentes tipos de globalização na história, que variam em termos de extensão geográfica (globais, hemisféricas e continentais) e do grau de conectividade (desde contatos esparsos, como o comércio do incenso árabe e seda chinesa, ${ }^{6}$ até casos de grande interdependência entre regiões distantes, como no Império romano: ver abaixo). ${ }^{7}$ Tais abordagens têm o potencial de aprimorar o nosso conhecimento sobre transformações culturais em contextos de conectividade aumentada, indo além de modelos de aculturação e difusão. Crucial nesse sentido é o conceito de glocalização - isto é, o fenômeno pelo qual tendências culturais globais são re-elaboradas em âmbito local (por exemplo, os cardápios nacionais do McDonald's). ${ }^{8}$

Polity Press, 2008; OLSTEIN, Daniel. Thinking history globally. Basingstoke: Palgrave Macmillan, 2014; KLEINBERG, Ethan \& PINCH, William. History and theory in a global frame. History and Theory, vol. 54, n. 4, Middletown, 2015, p. 1-4. A história global busca superar os limites das histórias nacionais, ainda dominantes na historiografia: cf. OLSTEIN, Daniel, op. cit. p. 4 (sobre o problema do nacionalismo metodológico que influenciou fortemente a escrita da história desde o século XIX). Para uma interessante reflexão sobre o desenvolvimento da história global e seus atuais impasses (por exemplo, a recente tendência "antiglobalizante" sinalizada pela eleição de Trump nos EUA e pelo "Brexit" no Reino Unido), ver MORELLI, Alexandre. Perspectivas globais e transnacionais: vida (e morte?) da história global. Estudos Históricos, vol. 30, n. 60, Rio de Janeiro, 2017, p. 5-16.

${ }_{6}$ PURCELL, Nicholas. Unnecessary dependences: illustrating circulation in pre-Modern large-scale history. In: BELICH, James; DARWIN, John; FRENZ, Margret; WICKHAM, Christopher (org.). The prospect of global history. Oxford: Oxford University Press, 2016, p. 65-79. O autor toma como estudo de caso o comércio do incenso entre o mar Vermelho e o Mediterrâneo na Antiguidade; tal comércio operava em escala global, mas envolvia inúmeros agentes e intermediários, cada qual sendo afetado pelo comércio global de maneira particular.

7 BELICH, James; DARWIN, John; FRENZ, Margret; WICKHAM, Christopher (org.), op. cit. p. 5; CONRAD, Sebastian, op. cit., p. 9, 91: "As a consequence, the potential of the approach [of global history] can best be exploited in studying periods when integration is sustained and of a certain density. Conversely, in historical epochs when connections remained spurious and integration is hardly palpable, it is much less productive - and possibly less efficient than other approaches, such as comparative history, which properly speaking are not global history". Sobre o interesse em identificar processos de globalização na Antiguidade e Idade Média, cf. CONRAD, Sebastian, op. cit., p. 111-113 (com bibliografia).

${ }^{8}$ Sobre o conceito de glocalização ou globalização local ver CLARKE, David. The consumer society and the postmodern city. Londres: Routledge, 2003. Os resultados desse processo vão muito além da mera aculturação, dados o enorme volume, a complexidade e a pluralidade das trocas culturais em um mundo globalizado. Uma boa definição da glocalização é dada por Robert Witcher: "universalização do particular e a particularização do universal" (WITCHER, Robert. Globalisation and Roman imperialism. In: HERRING, Edward \& LOMAS, Katherine (org.). The 
O Mediterrâneo apresenta-se como um contexto adequado para o estudo de conexões globais no passado distante. O reconhecimento da grande conectividade que caracteriza a história dessa região consolidou-se com a publicação de duas obras-chaves: The corrupting sea, de Peregrine Horden e Nicholas Purcell (2000), e Rethinking the Mediterranean, coletânea organizada por William Harris (2005). ${ }^{9}$ Desde então, tem-se deixado de pensar o Mediterrâneo como estando claramente dividido entre civilizações fixas no espaço e no tempo (gregos, romanos, fenícios, árabes, turcos, venezianos etc.). Ao contrário, cada vez mais exploram-se a conectividade entre essas diferentes culturas e a intensa mobilidade de pessoas, bens e ideias atravessando fronteiras. ${ }^{10} \mathrm{O}$ novo paradigma da "mediterraneanização" (tal como Ian Morris o denominou) é, ele próprio, um resultado da globalização moderna e seu impacto sobre a historiografia. ${ }^{11}$

Alguns estudiosos discutem mais diretamente a teoria da globalização e sua aplicabilidade ao Mediterrâneo antigo. Um bom exemplo é o estudo de Kostas Vlassopoulos sobre o período arcaico (800-500 a. C.), no qual o autor identifica vários casos em que a cultura grega foi glocalizada entre povos não gregos - como os etruscos na Itália e os citas no mar Negro. Vlassopoulos examina como esses povos se apropriaram de certos aspectos da cultura grega (arquitetura, escultura e escrita), re-elaborando-os segundo suas necessidades e tradições locais. ${ }^{12}$ Outro grande foco de estudos é o Império romano. Durante muito tempo, as transformações decorrentes da expansão romana foram interpretadas a partir da ideia tradicional de "romanização", que colocava Roma como o centro difusor de inovações culturais para os

emergence of state identities in Italy in the first millennium BC. Londres: Accordia Research Institute, 2000, p. 213-225).

9 HORDEN, Peregrine $\mathcal{E}$ PURCELL, Nicholas. The corrupting sea: a study of Mediterranean history. Oxford: Blackwell, 2000; HARRIS, William. The Mediterranean and ancient history. In: HARRIS, William (org.). Rethinking the Mediterranean. Oxford: Oxford University Press, 2005, p. 1-42.

${ }^{10}$ Atualmente é mais comum pensar a história do Mediterrâneo como um todo interligado, desde a Idade do Bronze (1200 a. C.) até o período moderno GUARINELLO, Norberto Luiz. Ordem, integração e fronteiras no Império romano: um ensaio. Mare Nostrum, vol. 1, São Paulo, 2010, p. 113-127; BROODBANK, Cyprian. The making of the middle sea. Londres: Thames and Hudson, 2013; HORDEN, Peregrine. Introduction. In HORDEN, Peregrine $\mathcal{E}$ KINOSHITA, Sharon (org.). A companion to Mediterranean history. Oxford: Wiley Blackwell, 2014, p. 1-7.

${ }^{11}$ MORRIS, Ian. Mediterraneanization. The Mediterranean Historical Review, vol. 18, n. 2, Londres, 2005, p. 30-55.

12 VLASSOPOULOS, Kostas. Greeks and Barbarians. Cambridge: Cambridge University Press, 2013, p. $230-40$. 
territórios conquistados. ${ }^{13}$ Como vários estudiosos já demonstraram, é problemática a ideia de que os povos conquistados teriam imitado a cultura romana na tentativa de tornar-se romanos. ${ }^{14}$ Ao contrário, trocas e influências culturais ocorriam a partir de diversos pontos, em diversos sentidos, e geravam diversos resultados. ${ }^{15}$ Em uma recente coletânea sobre o tema, Martin Pitts e Miguel Versluys oferecem novas interpretações das mudanças culturais nas províncias romanas, com base no paradigma da globalização. ${ }^{16}$ Tais

${ }^{13}$ Cf., por exemplo, WEBSTER, Jane $\mathcal{E}$ COOPER, Nick (org.). Roman imperialism: post-colonial perspectives. Leicester: University of Leicester Press, 1996; MATTINGLY, David John. Dialogues of power and experience in the Roman Empire. In: MATTINGLY, David John (org.). Dialogues in Roman imperialism. Power, discourse and discrepant experience in the Roman Empire. Portsmouth, RI: Journal of Roman Archaeology, 1997, p. 7-24; MATTINGLY, David John. Being Roman: expressing identity in a provincial setting. Journal of Roman Archaeology, vol. 17, Portsmouth, RI: Journal of Roman Archaeology, 2004, p. 5-25; MATTINGLY, David John. Imperialism, power and identity. Experiencing the Roman Empire. Princeton: Princeton University Press, 2011; TERRENATO, Nicola. Tam firmum municipium: The romanization of Volaterrae and its cultural implications. Journal of Roman Studies, vol. 88, Londres: Society for the Promotion of Roman Studies, 1998, p. 94-114; TERRENATO, Nicola. A tale of three cities. In: KEAY, Simon $\mathcal{E}$ TERRENATO, Nicola (org.). Italy and the West. Comparative issues in romanization. Oxford: Oxbow, 2001, p. 54-67; TERRENATO, Nicola. The clans and the peasants. Reflections on social structure and change in Hellenistic central Italy. In: VAN DOMMELEN, Peter $\mathcal{E}$ TERRENATO, Nicola (org.). Articulating local cultures. Power and identity under the expanding Roman Republic. Portsmouth RI: Journal of Roman Archaeology, 2007, p. 1322; VAN DOMMELEN, Peter. Cultural imaginings. Punic tradition and local identity in Roman Republican Sardinia. In: KEAY, Simon $\mathcal{E}$ TERRENATO, Nicola (org.). Italy and the West. Comparative issues in romanization. Oxford: Oxbow, 2001, p. 68-841; ROTH, Roman. Styling romanisation: pottery and society in Central Italy. Cambridge: Cambridge University Press, 2007.

${ }^{14}$ Para uma discussão recente da tese da "autoromanização" dos povos conquistados, cf. SCOPACASA, Rafael. Repensando a romanização: a expansão romana na Itália a partir das fontes historiográficas. Revista de História (USP), vol. 172, São Paulo: Universidade de São Paulo, 2015, p. 124-126. Uma pequena amostragem da vasta bibliografia sobre o assunto: WOOLF, Greg. Becoming Roman. The origins of provincial civilization in Gaul. Cambridge: Cambridge University Press, 1998; TERRENATO, Nicola. Tam firmum municipium: The romanization of Volaterrae and its cultural implications. Journal of Roman Studies, vol. 88, Londres: Society for the Promotion of Roman Studies, 1998, p. 94-114; PITTS, Martin. Globalising the local in Roman Britain: an anthropological approach to social change. Journal of Anthropological Archaeology, vol. 27, fasc. 4, Elsevier, 2008, p. 493-506; MATTINGLY, David John. Imperialism, power and identity. Experiencing the Roman Empire. Princeton: Princeton University Press, 2011; FLEMING, Maria Isabel d'Agostino (org.). I SIMPÓSIO DO LABORATÓRIO DE ARQUEOLOGIA ROMANA PROVINCIAL: REPRESENTAÇÕES DA ROMANIZAÇÃO NO MUNDO PROVINCIAL ROMANO. Revista do Museu de Arqueologia e Etnologia, Suplemento n. 18, São Paulo: Museu de Arqueologia e Etnologia da Universidade de São Paulo, 2013.

${ }^{15}$ Entretanto, desde os anos 1990, estudiosos favoráveis ao conceito de romanização reconhecem a necessidade de reformulá-lo, de maneira a dar conta do fato de que a dominação romana gerou resultados extremamente diferentes entre os povos conquistados; cf. TERRENATO, Nicola, op. cit.

${ }^{16}$ PITTS, Martin \& VERSLUYS, Miguel John (org.). Globalisation and the Roman world: world history, connectivity and material culture. Cambridge: Cambridge University Press, 2014. 
mudanças são abordadas não como simples reflexo da influência romana, mas como resultado da conectividade intensificada entre regiões distantes e, em alguns casos, previamente isoladas. ${ }^{17}$

Contudo, a fase inicial da expansão romana (séculos IV a II a. C.) é um importante período que, até agora, recebeu menos tratamento na perspectiva da história global. Este artigo identifica conexões globais que se desenvolveram durante o início da expansão romana na Itália e no Mediterrâneo (a disseminação da cerâmica de verniz negro, o consumo de vinho grego na Itália, e a popularização de ex-votos anatômicos). Será examinado como essas tendências globais se manifestaram localmente (isto é, se glocalizaram) na península itálica, onde um rico corpo de fontes escritas e materiais nos permite observar mudanças culturais em diferentes camadas sociais, das elites à população comum. Por fim, pretende-se usar os estudos de caso para refletir sobre espacialidades e fronteiras. Muito embora a Itália fosse o centro político da nascente hegemonia romana, os intercâmbios culturais entre a Itália e o mundo mediterrânico nesse período não podem ser adequadamente compreendidos através de um modelo centro-periferia unicamente: a conectividade entre as diversas regiões parece atravessar, ou mesmo subverter, a hierarquia geopolítica entre "centro" e "periferia". Como será discutido, a história global nos oferece modelos mais dinâmicos para pensar a reconfiguração de fronteiras nesse contexto de conectividade aumentada. ${ }^{18}$

\section{Entre a Itália e o Egeu: o vinho como sintoma de globalidade}

Em 168 a. C., os exércitos da República romana derrotaram o rei Perseu da Macedônia na batalha de Pydna; ele era o último líder grego a confrontar a "nuvem do ocidente", que nos úlimos 40 anos avançara sem parar. ${ }^{19}$ Àquela altura, vários outros grandes já haviam caído com rapidez espantosa: o cartaginês Aníbal, que chegara bem perto de aniquilar Roma em 216 a. C., finalmente rendeu-se em 202, pondo fim a séculos de supremacia cartaginesa no Mediterrâneo central; em 188 a. C. foi a vez do poderoso reino selêucida: seu rei, Antíoco III, desafiou Roma em 191 e pagou o preço três anos depois. A vitória final sobre Perseu em 168 consolidou a posição de Roma como

\footnotetext{
${ }^{17}$ Cf. PITTS, Martin, op. cit., p. 494-495, com bibliografia.

${ }^{18}$ Cf. CONRAD, Sebastian, op. cit., p. 117-18 (sobre a busca por "espaços históricos alternativos").

19 Sobre a imagem de Roma como "nuvem do ocidente": Políbio, 5.104.8.
} 
superpotência hegemônica no Mediterrâneo inteiro. Tal acontecimento era totalmente sem precedentes e seu impacto foi considerável.

Quase certamente, a ascensão espetacular de Roma não teria sido possível sem o apoio massivo dos aliados itálicos e suas tropas. ${ }^{20}$ Os itálicos vinham colaborando com Roma desde 270 a. C., após várias décadas de guerra sangrenta. ${ }^{21}$ Oficialmente, Roma reconhecia a independência dos seus aliados itálicos, ${ }^{22}$ suas principais obrigações eram enviar tropas regularmente e seguir a política externa romana. ${ }^{23}$ Por um lado, o acerto foi interessante para os itálicos: eles recebiam espólios de guerra e, possivelmente, terras. ${ }^{24}$ É também provável que Roma defendesse os privilégios de elites itálicas re-

\footnotetext{
${ }^{20}$ Na véspera da Segunda Guerra Púnica (218 a. C.), para cada dois cidadãos romanos havia três soldados aliados: CORNELL, Timothy. The conquest of Italy. In: WALBANK, Frank; ASTIN, Alan; FREDERIKSEN, Martin; OGILVIE, Robert (org.). Cambridge Ancient History, vol. 7.2. Cambridge: Cambridge University Press, 1989, p. 379. Quando Cipião Africano estava organizando sua expedição decisiva contra Aníbal em 205 a. C. - que viria a garantir a vitória romana na Segunda Guerra Púnica - ele obteve recursos e tropas de várias cidades da Itália central: Lívio 28.45.11-12.

${ }^{21}$ Durante muito tempo, o estudo da expansão romana na Itália dependeu muito de fontes historiográficas antigas (Políbio, Tito Lívio, Dionísio de Halicarnasso), escritas muito tempo depois dos eventos narrados, e de uma perspectiva romanocêntrica: cf. SCOPACASA, Rafael. Repensando a romanização: a expansão romana na Itália a partir das fontes historiográficas. Revista de História (USP), vol. 172, São Paulo: Universidade de São Paulo, 2015, p. 117-122; ECKSTEIN, Arthur. Mediterranean anarchy, interstate war and the rise of Rome. Berkeley: University of California Press, 2006); BURTON, Paul. Friendship and Empire. Roman diplomacy and imperialism in the middle Republic (353-146 BC). Cambridge: Cambridge University Press, 2011.

${ }^{22}$ Essa situação só mudou quando os itálicos receberam a cidadania romana, com a aprovação da lex Iulia em 90 a. C.: BISPHAM, Edward. From Asculum to Actium. The municipalisation of Italy from the social war to Augustus. Oxford: Oxford University Press, 2007, p. 161-172. Havia diversos tipos de comunidades políticas na Itália republicana (séculos IV-I a. C.): de maneira geral, cidades-estado predominavam na Itália tirrênica (ocidental) e meridional, enquanto que o versante oriental (ou "adriático") abrigava uma gama mais diversa de comunidades, como Estados territoriais de caráter "federal", tais como os Samnitas e Lucanos (cf. SCOPACASA, Rafael. Ancient Samnium: settlement, culture and identity between history and archaeology. Oxford: Oxford University Press, 2015, p. 209-237; SCOPACASA, Rafael. Identidade étnica na Itália antiga, séculos IV-I a. C.: fontes, problemas e possibilidades de estudo. Tempo (UFF), no prelo).

${ }^{23}$ Políbio, 6.21.5; cf. HARRIS, William. Rome in Etruria and Umbria. Oxford: Clarendon, 1971; BISPHAM, Edward, op. cit., p. 35; sobre tratados, cf. RICH, John. Treaties, allies and the Roman conquest of Italy. In: DE SOUZA, Philip \& FRANCE, John (org.). War and peace in ancient and medieval history. Cambridge: Cambridge University Press, 2008, p. 51-75.

${ }^{24}$ Espólios (móveis) de guerra: Lívio 31.20.7, 33.23.7, 33.37.12; a questão do acesso à terra é mais controversa: para a tese de que soldados itálicos veteranos podiam receber terras do Estado romano, cf. CORNELL, Timothy, op. cit., p. 379; SCOPACASA Rafael. Repensando a romanização: a expansão romana na Itália a partir das fontes historiográficas, op. cit., p. 129-133; para argumentos contrários, cf. ROSELAAR, Saskia Tessa. Public land in the Roman Republic: a social and economic history of Ager Publicus in Italy, 396-89 BC. Oxford: Oxford University Press, 2010, p. 193.
} 
primindo revoltas populares, como parece ter ocorrido nas cidades etruscas de Volsinii (264 a. C.) e Falerii (241 a. C.). ${ }^{25}$ Contudo, nem tudo era harmônico nesse relacionamento: por um lado, a ideia da Itália como quintal de Roma aparentemente já circulava no início do século III a. C. ${ }^{26}$ Os itálicos, por sua vez, não parecem ter se considerado subalternos: de acordo com Políbio, na batalha de Telamon contra uma invasão gaulesa (225 a. C.), os itálicos lutaram ao lado dos romanos não por subserviência, mas pelo anseio de se defenderem dos invasores. ${ }^{27}$ Poucos anos depois, na segunda Guerra Púnica (218-202 a. C.), muitos itálicos rapidamente abandonaram a aliança com Roma após a estrondosa vitória cartaginesa na batalha de Cannae (216 a. C.). ${ }^{28}$ Mesmo após décadas de subordinação, os estados itálicos aparentemente mantiveram vivo o seu senso de independência e autonomia. ${ }^{29}$ Esse frágil equilíbrio entre colaboração e competição teria se intensificado no pós-202 a. C., quando Roma adotou uma política externa menos flexível para com seus aliados, na tentativa de impedir novas traições. ${ }^{30}$

O terremoto geopolítico provocado pelo avanço romano-itálico sobre o Mediterrâneo, e mais especificamente sobre o mundo grego, causou grandes transformações. Algumas são bem conhecidas, como a dita "onda helenizante" que tomou conta de Roma no século II a. C.: esse foi o momento em que a elite romana passou a importar em massa vários elementos da cultura grega, dando origem a diversas novas manifestações na literatura, religião, filosofia, artes visuais e arquitetura. ${ }^{31}$ Contudo, a "onda helenizante" afetou não só Roma, como também a Itália em geral: um bom exemplo é a construção, por toda a península, de templos monumentais em mármore, de acordo com

\footnotetext{
${ }^{25}$ Políbio 1.65.2; Zonaras 8.7; HARRIS, William. Volsinii and Rome, 400-100 BC. Volsinii e la dodecapoli etrusca. Annali della fondazione per il Museo "Claudio Faina", vol. 2, Orvieto: Museo Claudio Faina, 1985, p. 143-56. É importante ressaltar que não há consenso de que essas revoltas foram de fato "populares", contra as elites locais - e não, por exemplo, revoltas das cidades inteiras contra Roma: cf. BISPHAM, Edward, op. cit., p. 53, nota 1.

${ }^{26}$ Políbio 1.6.6, 2.20.10; cf. SCOPACASA, Rafael. Old habits die hard: Samnites, Rome, and the perception of international relations in Republican Italy, c. 350-200 BC. Historia: Zeitschrift für Alte Geschichte (no prelo); SERRATI, John. Neptune's altars: the treaties between Rome and Carthage (509-226 BC). Classical Quarterly, vol. 56, Cambridge: Cambridge University Press, 2006, p. 120-129; FRONDA, Michael. Between Rome and Carthage. Southern Italy during the Second Punic War. Cambridge: Cambridge University Press, 2010, p. 24.

${ }^{27}$ Políbio 2.23.11-13; cf. FRONDA, Michael, op. cit., p. 28.

${ }^{28}$ Lívio 22.61.

${ }^{29}$ FRONDA, Michael, op. cit., p. 241.

${ }^{30}$ BISPHAM, Edward, op. cit., p. 131-142.

${ }^{31}$ WALLACE-HADRILL, Andrew. Rome's cultural revolution. Cambridge: Cambridge University Press, 2008.
} 
os modelos arquitetônicos helenísticos. ${ }^{32}$ Tais modelos foram apropriados e reinterpretados pelas elites itálicas, ansiosas para demonstrar familiaridade com esses símbolos de prestígio e cosmopolitismo - possivelmente, de modo a sinalizar a sua própria competência cultural e autodeterminação. ${ }^{33}$ Ao mesmo tempo, os modelos importados foram rapidamente alterados de acordo com convenções locais: daí o surgimento de tipos híbridos, como o Odeion de Pompeia e o templo-teatro de Pietrabbondante, que misturavam elementos helenísticos e itálicos (como o "cânone etrusco" de colunas à frente do tempo, diferente do peristilo grego). ${ }^{34}$

No entanto, é também possível identificar processos de glocalização através de vestígios arqueológicos menos chamativos ou monumentais. Objetos de cerâmica, por exemplo, estão entre os artefatos mais duráveis da Antiguidade; além disso, por serem uma tecnologia básica para o consumo de alimentos e bebidas, objetos de cerâmica são indicadores confiáveis de práticas do cotidiano. ${ }^{35}$ No contexto que nos interessa, evidências cerâmicas indicam que hábitos alimentares transformam-se bastante na Itália no final do século III e II a. C. A variedade de alimentos importados parece aumentar dramaticamente durante esse período.

Um importante indicador dessas mudanças é o maior número de ânforas de vinho grego importado do mar Egeu/ Mediterrâneo oriental. Sabe-se que o vinho já era produzido na Itália desde a Idade do Ferro (1000 a. C.); ${ }^{36}$ em vista disso, a enxurrada de vinhos gregos a partir do final do século III a. C. teria representado um aumento considerável das possibilidades de consumo. Ânforas gregas de vinho começam a aparecer por toda a Itália, desde a Sicília até o Veneto no norte (figura 1, que reúne uma amostragem

\footnotetext{
${ }^{32}$ ZANKER, Paul (org.). Hellenismus in Mittelitalien. Kolloquium in Göttingen vom 5 bis 9 Juni 1974. Gottingen: Vanderhoeck und Ruprecht, 1976.

33 WALLACE-HADRILL, Andrew, op. cit., p. 99.

${ }^{34}$ LA REGINA, Adriano. Il Sannio. In: ZANKER, Paul (org.). Hellenismus in Mittelitalien. Kolloquium in Göttingen vom 5 bis 9 Juni 1974. Gottingen: Vanderhoeck und Ruprecht, 1976, p. 219-44.

35 Sobre abordagens à cerâmica e sua relação com práticas de consumo, cf. WOOLF, Greg. Becoming Roman: the origins of provincial civilisation in Gaul. Cambridge: Cambridge University Press, 1998, p. 169-205; PITTS, Martin. Globalising the local in Roman Britain: an anthropological approach to social change. Journal of Anthropological Archaeology, vol. 27, fasc. 4, Albuquerque: Elsevier, 2008, p. 493-506.

${ }^{36}$ SCOPACASA, Rafael. Gender and ritual in ancient Italy: a quantitative approach to grave goods and skeletal evidence in pre-Roman Samnium. American Journal of Archaeology, vol. 118, fasc. 2, Boston: The Archaeological Institute of America, 2014, p. 241-66.
} 
de dados publicados). ${ }^{37}$ Ânforas de Rodes - uma cidade-ilha no mar Egeu e importante centro comercial - tendem a ser mais numerosas do que as de outros centros exportadores (Cós, Chios e Cnido; esse ponto será retomado adiante) ${ }^{38}$ Em certa medida, o aparente aumento na importação de vinhos gregos provavelmente estava relacionado à consolidação da supremacia romana na Grécia após a batalha de Pydna em 168 a. C.: a conquista parece ter aberto novas oportunidades comerciais que romanos e itálicos rapidamente souberam aproveitar. ${ }^{39}$

Entretanto, a crescente demanda por vinho grego importado não pode ser explicada como simples reflexo da abertura dos mercados gregos. Como dito acima, há sinais de que tanto romanos quanto itálicos estavam ativamente interessados em adquirir elementos culturais do mundo grego, que remetessem ao estilo de vida das elites helenísticas. ${ }^{40}$ Assim como a construção generalizada de templos, o consumo de vinho grego poderia representar um esforço, por parte das comunidades itálicas, de negociar a sua nova posição no contexto de conexões globais. Para desenvolver a análise, podemos usar como estudo de caso o centro urbano de Monte Vairano na Itália central, onde boa parte das ânforas gregas foram encontradas (figura 1). ${ }^{41}$ Esse sítio arqueológico, cujo nome antigo é desconhecido, parece ter sido uma importante capital dos samnitas, povo itálico mencionado nas fontes greco-romanas como grandes rivais de Roma na península. ${ }^{42}$ Enquanto algumas

37 Conforme já admitido, a distribuição de ânforas oferece-nos apenas uma imagem parcial das práticas de consumo. Certamente havia outros recipientes utilizados para o transporte de vinho, azeite e outros alimentos, feitos de materiais perecíveis como madeira ou peles, difíceis de detectar no registro arqueológico. Mesmo assim, as ânforas ródias indicam uma importante mudança nos hábitos de consumo não somente em Monte Vairano, mas na Itália central em geral.

${ }^{38}$ MARENGO, Silvia $\&$ PACI, Gianfranco. Per la circolazione delle anfore rodie e tardo-repubblicane in area adriatica. In: BUONOPANE, Alfredo (org.). Est enim ille flos Italiae. Vita economica e sociale nella Cisalpina romana. Verona, 2008, p. 314.

${ }^{99}$ Cf. ROSELAAR, Saskia Tessa. Mediterranean trade as a process of integration between Romans and Italians. In: Idem (org.). Processes of integration and identity formation in the Roman Republic. Leiden: Brill, 2012, p. 141-158.

${ }^{40}$ Importante aqui é o conceito de "credenciais culturais helênicas": cf. DENCH, Emma. From Barbarians to new men: Greek, Roman and modern perceptions of the Central Apennines. Oxford: Clarendon, 1995). Certamente havia admiração da cultura grega por parte dos romanos e outros itálicos; entretanto, é importante lembrar que os romanos eram também capazes de desprezar os gregos e sua cultura: cf. GRUEN, Erich. Culture and national identity in Republican Rome. Ithaca NY: Cornell University Press, 1992, p. 223-271.

${ }^{41}$ Sobre a distribuição de ânforas gregas na Itália, cf. MARENGO, Silvia \& PACI, Gianfranco, op. cit.

${ }^{42}$ Lívio 9.31.4, 10.39.7; cf. DE BENEDITTIS, Gianfranco. L'abitato di Monte Vairano ovvero Aquilonia. In: Sannio: Pentri e Frentani dal VI al I secolo a. C. Roma: De Luca, 1980, p. 321-341. 
ânforas em Monte Vairano vêm da própria Itália (tipos Dressel 1A e 1B), ânforas gregas são quatro vezes mais numerosas: ao menos 40 delas foram identificadas em Monte Vairano com base nos carimbos nas alças. ${ }^{43}$ Em conformidade com a tendência geral, a grande maioria das ânforas gregas em Monte Vairano vem de Rodes, e data de entre o final do século III e II a. C. ${ }^{44}$

Por se tratar de um centro urbano localizado no interior montanhoso da Itália central, longe dos portos litorâneos e de difícil acesso, é plausível que a importação das ânforas ródias até Monte Vairano tenha sido custosa e complicada logisticamente. Por isso, parece provável que membros da elite local tenham tido um papel fundamental na importação desse vinho, já que tais indivíduos teriam os recursos necessários para financiar o transporte das ânforas até as montanhas. Parece curioso que a elite interiorana de Monte Vairano preferiu investir pesadamente na importação de vinho ultramarino - quando, provavelmente, teria sido mais simples e barato dar prioridade a vinhos produzidos localmente (a Campânia, região vizinha, era um grande centro produtor). A determinação das elites de Monte Vairano em esbanjar recursos, tempo e energia na aquisição de vinho grego ultramarino, parece revelar um esforço consciente de construir uma autoimagem globalizada. Ou seja, essa elite provinciana estaria ansiosa para afirmar (e talvez exagerar) a sua inclusão nas novas redes globais, e a sua própria familiaridade com o novo Mediterrâneo globalizado. Tal esforço faria sentido como estratégia de legitimação perante a população comum do local, assim como num contexto de competição por "credenciais cosmopolitas" com figurões de cidades vizinhas. De uma forma ou de outra, o vinho ródio parece ter se glocalizado em Monte Vairano como símbolo de prestígio e sofisticação cultural, com possíveis conotações de autonomia política. Não parece adequado descrever esse processo como "helenização": os consumidores, por mais provincianos que fossem, não estavam absorvendo passivamente a cultura grega, mas apropriando-se de artigos gregos e ressignificando-os.

Ao mesmo tempo, não estamos tratando somente de influência grega sobre comunidades itálicas. A presença de vinho grego na Itália pode também ser vista como um sinal da transformação do próprio mundo grego,

\footnotetext{
${ }^{43}$ DE BENEDITTIS, Gianfranco $\mathcal{E}$ BEVILACQUA, Gabriella. Le anfore, Bolli Rodi. In: Sannio: Pentri e Frentani dal VI al I secolo a. C. Roma: De Luca, 1980, p. 306-8, 342-8.

${ }^{44}$ Este espaço compreende os quadrados D3-4 e E3-4: DE BENEDITTIS, Gianfranco. L'abitato di Monte Vairano ovvero Aquilonia. In: Sannio: Pentri e Frentani dal VI al I secolo a. C. Roma: De Luca, 1980, p. 321-341.
} 
em resposta à hegemonia romana. Parece especialmente relevante que a esmagadora maioria das ânforas gregas encontradas na Itália vêm de Rodes especificamente (pelo menos no que diz respeito ao material arqueológico publicado). Por um lado, a polis-ilha de Rodes havia sido tradicionalmente um grande centro comercial. Mas é também significativo que Rodes foi uma grande aliada de Roma durante a intervenção romana no mundo grego, entre 200 e 168 a. C. ${ }^{45}$ Embaixadores ródios formavam a missão diplomática que foi a Roma em 200 a. C. para pedir ajuda contra a (suposta) aliança entre a Macedônia e o reino selêucida, que ameaçava subjugar toda a Grécia. O apoio de Rodes foi essencial nas subsequentes vitórias romanas sobre o reino selêucida em 188 a. C. e os macedônios em 168 a. C. ${ }^{46}$ Considerando esse contexto geopolítico, fica aparente que o boom de vinho ródio na Itália pode ter sido um aspecto da criação de uma nova ordem mundial. A presença romana na Grécia provavelmente reconfigurou a espacialidade dos contatos no Mediterrâneo, criando novas dinâmicas de interação que possuíam as suas próprias regras. A alteração do sistema geopolítico criou novas oportunidades para estados "menores" como Rodes: graças à sua associação com Roma, essa polis-ilha ganhou uma projeção que, de outra maneira, seria bastante improvável no mundo helenístico - o qual, antes da chegada de Roma, encontrava-se num equilíbrio de poder manejado por um clube seleto de três grandes reinos (Egito ptolemaico, Macedônia, e o reino selêucida). Em outras palavras: como tantas outras globalizações na história, a globalização promovida pela hegemonia romana no Mediterrâneo no século II a. C. parece ter gerado vencedores e perdedores - ou seja, parece ter produzido novas desigualdades. ${ }^{47}$ É tentador interpretar o desequilíbrio numérico entre ânforas ródias e de outros centros gregos na Itália como um reflexo de vantagens desigualmente distribuídas entre os estados gregos na nova ordem global encabeçada por Roma. Aparentemente, alguns estados prosperaram com a nova conectividade mais do que outros.

A presença romana também abriu novas modalidades de intercâmbio cultural na própria Grécia: um bom estudo de caso é o porto livre na ilha de Delos. Por conta do decreto romano que criou o porto livre em 166 a. C.,

\footnotetext{
${ }^{45}$ Para uma discussão atualizada da relação entre Roma e Rodes, cf. BURTON, Paul, op. cit.

${ }^{46}$ Cf. ECKSTEIN, Arthur. Rome enters the Greek East. From anarchy to hierarchy in the Eastern Mediterranean. Oxford: Blackwell, 2012.

${ }^{47}$ Sobre a relação entre globalização e desigualdade, cf. CONRAD, Sebastian, op. cit., p. 213 (com bibliografia); cf. também MORRIS, Ian, op. cit., p. 46-51 (sobre os vencedores e perdedores da globalização no Mediterrâneo arcaico, a partir de um estudo de caso na Sicília).
} 
essa ilha no mar Egeu passou a abrigar uma grande comunidade internacional de mercadores, muitos deles romanos e itálicos. Evidente no registro arqueológico e epigráfico de Delos é a introdução de cultos religiosos trazidos de Roma e da Itália, sobretudo os Compitalia, o festival anual dos Lares (divindades protetoras domésticas). ${ }^{48}$ Aqui, também, podemos detectar a glocalização em funcionamento: há indícios de que o festival romano-itálico dos Compitalia sofreu uma série de adaptações em Delos, resultantes do contexto singular da ilha. Sinal disso é a presença, nas inscrições, do termo grego kompitaliastai. O termo se refere, aparentemente, a um grupo de escravos encarregados de supervisionar a execução dos Compitalia. ${ }^{49}$ Tal prática não parecia existir em Roma ou na Itália, onde a organização dos Compitalia cabia aos cidadãos livres, os chefes das casas cujos Lares eram cultuados no festival (embora escravos também participassem dos ritos, mas em outras capacidades). O próprio termo kompitaliastai é uma inovação grega: não há equivalentes conhecidos em latim ou nas línguas itálicas. A criação de um grupo de escravos para organizar os Compitalia em Delos provavelmente deveu-se ao fato de que os comerciantes romanos e itálicos, donos das residências cujos Lares eram celebrados no ritual, encontravam-se frequentemente fora da ilha a negócios..$^{50}$

\section{Consumo em massa: o caso da cerâmica de verniz negro}

A produção e o consumo em massa são importantes objetos de estudo da história global..$^{51} \mathrm{O}$ surgimento de commodities globais, como açúcar, café e petróleo, é uma característica da economia-mundo moderna. Dado que fenômenos comparáveis à globalização moderna podem ser identificados no passado distante (ver acima), muitos estudiosos buscam identificar a disseminação de bens de consumo em larga escala em economias ditas pré-capitalistas. Novamente, o caso do Mediterrâneo sob a ascensão de Roma nos oferece bons estudos de caso. Um exemplo é a disseminação de um artigo de

\footnotetext{
${ }^{48}$ Sobre os Compitalia em Delos, cf. FLOWER, Harriet. The dancing Lares and the serpent in the garden: religion at the Roman street corner. Princeton: Princeton University Press, 2017, p. 175-191.

${ }^{49}$ FLOWER, Harriet., op. cit., p. 175-176.

${ }^{50}$ FLOWER, Harriet., op. cit., p. 184.

${ }^{51}$ Cf. ROBINSON, Francis. Global history from an Islamic angle. In: BELICH, James: DARWIN, John: FRENZ, Margret; WICKHAM, Christopher. (org.). The prospect of global history. Oxford: Oxford University Press, 2016, p. 127-45, esp. p. 140, em que o autor discute os casos de commodities produzidas e consumidas em massa a partir do período moderno como café, açúcar e ópio.
} 
consumo que tornou-se verdadeiramente universal no Mediterrâneo entre os séculos IV e I a. C.: a cerâmica de verniz negro (black gloss ware).

Apesar de variar bastante dependendo da região e do período, a cerâmica de verniz negro (doravante $\mathrm{CVN}$ ) possui algumas características marcantes: é feita de argila depurada e fina (resistente e não quebradiça), produzida no torno ou com fôrmas, de superfícies lisas e regulares, cobertas com o característico verniz negro e lustroso, resistente a esfoladuras. ${ }^{52}$ Suas origens podem ser situadas em oficinas atenienses do período clássico (século $\mathrm{V}$ a. C.); já no final do século V e início do IV a. C., a CVN estava sendo exportada para a Itália, onde logo passou a ser fabricada localmente. Nos séculos III e II a. C., a CVN espalhou-se pela Itália; os exemplares recuperados tendem a ser altamente padronizados, de provável fabricação em grandes oficinas etruscas e campanas. ${ }^{53}$ Até recentemente, a disseminação e padronização da CVN na Itália eram consideradas um reflexo do imperialismo romano nascente. Em linhas gerais, esta tese mantém que o boom da CVN estava vinculado à mercantilização da economia italiana por parte de Roma, com a criação de grandes latifúndios monocultores (vinho e azeite) trabalhados por escravos e voltados para exportação. Esse novo sistema econômico teria favorecido os grandes portos da Campânia e Etrúria, por onde o vinho e o azeite escoavam para o exterior. Portanto, o agrobusiness romano teria promovido crescimento econômico na Campânia e Etrúria, e esse processo estaria refletido na ampla disseminação de CVN etrusca e campana. ${ }^{54}$ Recentemente, a tese da CVN como termômetro da romanização vem sendo questionada: mesmo se interesses romanos acabaram favorecendo a produção em massa da CVN na Etrúria e Campânia, é também verdade que vários centros de produção se desenvolveram em outras regiões itálicas, dando origem a diversos tipos regionais de CVN que ainda estão sendo catalogados. ${ }^{55}$ Todavia, a consolidação da hegemonia romana na Itália ao longo do século III a. C. muito provavelmente ajudou na disseminação ampla e capilar da CVN pela península. De especial importância parece ter sido a construção da rede de estradas romanas a partir de 312 a. C.: tais estradas abriram novas oportu-

\footnotetext{
${ }^{52}$ SPARKES, Brian \& TALCOTT, Lucy. Black and plain pottery of the 6th, 5th and 4th centuries BC. Princeton N. J.: American School of Classical Studies at Athens, 1970; ROTH, Roman, op. cit.

${ }^{53}$ MOREL, Jean Paul. The transformation of Italy, 300-133 BC: the evidence of archaeology. In Cambridge Ancient History, vol. VIII. Cambridge: Cambridge University Press, 1989, p. 477-516.

${ }^{54}$ MOREL, Jean Paul, op. cit.

${ }^{55}$ ROTH, Roman. Before sigillata: black-gloss pottery and its cultural dimensions. In: EVANS, Jane De Rose (org.). A companion to the archaeology of Republican Italy. Oxford: Wiley-Blackwell, p. 81-96.
} 
nidades para a circulação de pessoas, bens e tecnologias, possibilitando a extensão da produção e consumo da CVN para além dos grandes centros etruscos e campanos, através de novas rotas de fornecimento e comércio. Evidentemente, a nova conectividade das estradas não era neutra: uma das principais funções da malha viária romana parece ter sido ligar as várias colônias romanas entre si, e todas elas a Roma. ${ }^{56}$

A ampla disseminação da CVN pode ser tomada como um caso de "universalização do particular", frequentemente observado em contextos de globalização: ${ }^{57}$ o que antes era uma tecnologia totalmente particular a Atenas clássica (século $\mathrm{V}$ a. C.) passa a estar presente em praticamente toda cidade, aldeia e fazenda na Itália, assim como em outras partes do Mediterrâneo. Parecemos estar diante de uma tendência global que sofreu apropriações e adaptações locais, e que estimulou transformações culturais em diversos sentidos. Para observar tais mudanças em detalhe, podemos novamente concentrar-nos na região do Samnium como estudo de caso. Durante a Idade do Ferro (c. 1000-400 a. C.) predominou no Samnium um tipo de cerâmica grosseira e feita à mão, chamada impasto, até a chegada dos primeiros exemplares de $\mathrm{CVN}$ importados da Grécia no final do século $\mathrm{V}$ a. C. ${ }^{58}$ A chegada da CVN não levou ao abandono do impasto: ambos os tipos passaram a ser usados conjuntamente, tanto em contextos de elite como fora deles. ${ }^{59}$ Nos cemitérios, por exemplo, a CVN é encontrada em tumbas luxuosas assim como

\footnotetext{
${ }^{56}$ Para uma discussão aprofundada e atualizada sobre o conceito de globalização e o seu potencial para o estudo do mundo romano, cf. PITTS, Martin $\mathcal{E}$ VERSLUYS, Miguel John (org.). Globalisation and the Roman world: world history, connectivity, and material culture. Cambridge: Cambridge University Press, 2014.

${ }^{57}$ Sobre a universalização do particular como característica da globalização, cf. WITCHER, Robert, op. cit.

${ }^{58}$ PARISE BADONI, Franca $\&$ RUGGIERI GIOVE, Maria. Alfedena, la necropoli di campo Consolino: scavi, 1974-1979. Chieti: Soprintendenza Archeologica dell'Abruzzo, 1981. Nos séculos IV a II a. C., a CVN passou a estar presente em virtualmente todos os sítios arqueológicos samnitas conhecidos, e não tarda em aparecer a produção local. Monte Vairano: DE BENEDITTIS, Gianfranco. Monte Vairano: tratturi, economia e viabilità. Conoscenze, vol. 6, Campobasso: Soprintendenza Archeologica del Molise, 1990, p. 13-27; Beneventum: GIAMPAOLA, Daniela. Benevento. Dal centro indigena alla colonia romana. In: Studi sull'Italia dei Sanniti. Roma: Electa, 2000, p. 36-46; Larino: DI NIRO, Angela. La zona frentana tra IV e I sec. a. C. In: CAPINI, Stefania \& DI NIRO, Angela (org.). Samnium. Archeologia del Molise. Roma: Quasar, 1991, p. 131-134.

${ }^{59}$ É importante ressaltar que os especialistas já identificaram tipos distintamente locais ou regionais de cerâmica de verniz negro na Itália central, embora o material deva ainda ser catalogado e publicado: KANE, Susan. Life "on the edge": a view from the Abruzzo. In: LOCK, Gary \& FAUSTOFERRI, Amalia (org.). Archaeology and landscape in Central Italy: papers in memory of John A. Lloyd. Oxford: School of Archaeology, 2008, p. 93-103. (Oxford University School of Archaeology: monographs 69)
} 
em sepulturas de inumação mais humildes e austeras. ${ }^{60}$ De modo semelhante, a CVN está presente tanto em ricos templos monumentais como em modestos altares rurais; em casarões de elite e pequenas aldeias interioranas. ${ }^{61}$

A figura 2 reúne uma amostragem de recipientes de cerâmica no Samnium entre os séculos III e II a. C. ${ }^{62}$ Embora a amostra seja incompleta e inclua apenas dados arqueológicos publicados, ela sugere uma possível tendência: a grande maioria dos recipientes de CVN consiste de pequenas tigelas, copos, kylikes e outras taças pequenas para uso individual (kantharoi, skyphoi, taças). Em contraste, a cerâmica de impasto geralmente consiste de recipientes muito

${ }^{60}$ Sepulturas "de elite": TAGLIAMONTE, Gianluca. I Sanniti. Caudini, Irpini, Pentri, Carricini, Frentani. Milão: Longanesi, 1996, p. 208-9 (por exemplo a sepultura 23 na necrópole de Larino-Carpineto, utilizada entre os séculos V e II a. C.); sepulturas "humildes": DI NIRO, Angela. Il sepolcreto sannitico di Gildone. Conoscenze, vol. 5, Campobasso: Soprintendenza Archeologica del Molise, 1989, p. 27-36; MACCHIAROLA, Ida. I corredi del sepolcreto di Gildone. Conoscenze, vol. 5, Campobasso: Soprintendenza Archeologica del Molise, 1989, p. 37-79 (um catálogo das sepulturas na pequena necrópole rural de Gildone, utilizada entre os séculos V e III a. C.).

${ }^{61}$ Larino: DI NIRO, Angela. Larino: la città elenistica e romana. In: Sannio. Pentri e Frentani dal VI al I sec. a. C. Roma: De Luca, 1980, p. 286-306; DI NIRO, Angela. La zona frentana tra IV e I sec. a. C. In: CAPINI, Stefania \& DI NIRO, Angela (org.). Samnium. Archeologia del Molise. Roma: Quasar, 1991, p. 131-134; San Giovanni in Galdo: STEK, Tesse. Cult places and cultural change in Republican Italy. A contextual approach to religious aspects of rural society after the Roman conquest. Amsterdam: University of Amsterdam Press, 2009.

${ }^{62}$ Os dados vêm dos seguintes sítios arqueológicos, cujo material foi publicado ao todo ou em parte: Gildone (DI NIRO, Angela. Il sepolcreto sannitico di Gildone. Conoscenze, vol. 5, Campobasso: Soprintendenza Archeologica del Molise, 1989, p. 27-36; MACCHIAROLA, Ida. I corredi del sepolcreto di Gildone. Conoscenze, vol. 5, Campobasso: Soprintendenza Archeologica del Molise, 1989, p. 37-79); Alfedena (PARISE BADONI, Franca $\&$ RUGGIERI GIOVE, Maria, op. cit.); Larino-Carpineto (TAGLIAMONTE, Gianluca, op. cit.), Guglionesi (DI NIRO, Angela. Guglionesi. Necropoli arcaica. Conoscenze vol. 3, Campobasso, Soprintendenza Archeologica del Molise, 1986, p. 153-64); Termoli (DI NIRO, Angela. Necropoli arcaiche di Termoli e Larino. Campagne di scavo 1977-78. Campobasso, Soprintendenza archeologica e per i beni architettonici artistici e storici del Molise, 1981); Campochiaro (CAPINI, Stefania. 1980. Il santuario di Ercole a Campochiaro. In Sannio. Pentri e Frentani dal VI al I sec. a. C. Roma: De Luca, 1980, p. 197-217); Pietrabbondante (Sannio. Pentri e Frentani dal VI al I sec. a. C. Roma: De Luca, 1980); Schiavi d'Abruzzo (LAPENNA, Sandra. La stipe votiva di Schiavi. In: CAMPANELLI, Adele \& FAUSTOFERRI, Amalia (orgs.). I luoghi degli dei. Sacro e natura nell'Abruzzo italico. Chieti. Soprintendenza Archeologica dell'Abruzzo, 1997, p. 117-26); San Buono (FAUSTOFERRI, Amalia. L'area sacra di Fonte San Nicola: i votivi. In: CAMPANELLI, Adele. \& FAUSTOFERRI, Amalia (orgs.). I luoghi degli dei. Sacro e natura nell'Abruzzo italico. Chieti. Soprintendenza Archeologica dell'Abruzzo, 1997, p. 99-109), San Giovanni in Galdo (STEK, Tesse, op. cit.), Gildone (DI NIRO, Angela. Cercemaggiore-Gildone: la Casa, le Tombe e il Sacello. In: CAPINI, Stefania $\&$ DI NIRO, Angela (orgs.). Samnium: Archeologia del Molise. Roma: Quasar, 1991, p. 121-26); Larino (DI NIRO, Angela. Larino: la città elenistica e romana. In: Sannio. Pentrie e Frentani dal VI al I sec. a. C. Roma: De Luca, 1980, p. 286-306), Monte Vairano (DE BENEDITTIS, Gianfranco. Monte Vairano: La casa di LN. Catalogo della mostra. Campobasso: Studio Emmezeta, 1988), Fonte del Romito (RAININI, Ivan. Capracotta: l'abitato sannitico di Fonte del Romito. Roma: Gangemi, 1996). 
maiores, como caldeirões e tachos (ollae). Portanto, se a presente amostra for representativa, ela parece sugerir que a adoção da CVN estaria associada a uma ênfase no ato individual de consumir alimentos e bebidas, limitando o impasto aos grandes recipientes para preparação e/ou estocagem. Evidentemente, antes da chegada da CVN, havia no Samnium pequenas taças, copos e tigelas de impasto para uso individual. Entretanto, tais recipientes não eram muito diferentes dos grandes caldeirões, tachos ou ânforas: todos (ou quase todos) eram feitos à mão, com argila pouco depurada e quebradiça. Com a chegada da CVN, parece ocorrer uma diferenciação nítida entre o preparo e/ ou consumo comunal de alimentos (grandes tachos de impasto), e a ingestão individual de comida e bebida (taças, copos e tigelas de CVN mais "refinada"). Para desenvolvermos a análise, uma amostra maior e mais completa seria necessária; contudo, a presente amostragem já nos permite formular algumas hipóteses sobre o significado histórico da adoção da CVN no Samnium. Considerando que, no Mediterrâneo em geral, a CVN também era produzida na forma de recipientes maiores como crateras e ânforas, parece plausível que houvesse, no Samnium, uma demanda específica por CVN na forma de recipientes pequenos. ${ }^{63}$ Isso sugere que a CVN estava sendo consumida como artigo especializado. Através desse novo tipo de cerâmica, o ato de ingerir individualmente o alimento estava sendo claramente diferenciado do ato de cozinhar, armazenar, ou consumir coletivamente a partir de um mesmo tacho ou caldeirão comunal. Por esse ponto de vista, é possível que a CVN tenha sido adotada como instrumento para expressar novas dinâmicas sociais referentes à alimentação e/ou status social, possivelmente ligadas a novas regras de etiqueta, tornando o ato de comer e beber algo mais individualizado e "refinado".

Por outro lado, é também possível que a própria CVN tenha estimulado novas atitudes e dinâmicas sociais no Samnium. Potencialmente, o uso da CVN como instrumento para "individualizar" o consumo de alimentos poderia estar ligado aos atributos materiais desse novo estilo de cerâmica, claramente diferente do impasto pelas suas superfícies duras, lisas, regulares e reluzentes. Estaríamos, aqui, diante da complicada questão da "agência dos objetos". ${ }^{64}$ Evidentemente, o significado dos objetos não é intrínseco, mas va-

\footnotetext{
${ }^{63}$ Para um panorama da cerâmica de verniz negro, ver RASMUSSEN, Tom \& SPIVEY, Nigel. Looking at Greek vases. Cambridge: Cambridge University Press, 1991.

${ }^{64}$ Para uma recente discussão sobre a "agência de objetos"/cultura material no mundo romano, ver PITTS, Martin \& VAN OYEN, Astrid. What did objects do in the Roman world? Beyond
} 
ria dependendo de como o objeto é usado ou interpretado (ver acima, sobre o vinho ródio). Contudo, é concebível que os próprios objetos, e seus atributos físicos, possam favorecer certas atitudes e comportamentos sociais em detrimento de outros - especialmente em contextos de produção e consumo em massa, como parece ter sido o caso da CVN. A adoção de CVN no Samnium é, possivelmente, um caso em que cultura material globalizada influenciou e transformou o comportamento social de consumidores locais, por conta de seus atributos formais e materiais. Em última análise, os dados disponíveis ainda não nos permitem determinar em que medida esse teria sido o caso.

\section{Ex-votos anatômicos: "romanização religiosa" ou tendência global?}

Além da CVN, existem outros objetos que possibilitam um entendimento das conexões globais no Mediterrâneo sob a nascente hegemonia romana. Do ponto de vista arqueológico, a disseminação de ex-votos anatômicos é uma das tendências mais marcantes na Itália entre os séculos IV e II a. C., paralelamente à disseminação da CVN. ${ }^{65}$ Durante a Idade do Ferro (c. 1000400 a. C.), objetos normalmente dedicados em santuários itálicos consistiam de estatuetas de bronze, vasos de cerâmica, joias e, em menor medida, armas e armaduras. ${ }^{66}$ Em contrapartida, a partir de 350 a. C., observa-se um número crescente de ex-votos de terracota que representam membros e órgãos humanos, principalmente cabeças, pés, mãos, braços, pernas e órgãos reprodutivos. ${ }^{67}$ Até recentemente, acreditava-se que esse novo tipo de ex-voto originara-se nos arredores de Roma, já que as mais antigas peças conhecidas vêm do Lácio e da Etrúria. ${ }^{68}$ Fora dessas regiões, ex-votos anatômicos de terracota passam a ser especialmente numerosos nos lugares onde colônias romanas foram fundadas, embora tais objetos também estejam presentes em

\footnotetext{
representation. In: Idem (org.). Materialising Roman histories. Oxford: Oxbow Books, 2017, p. 3-20.

${ }^{65}$ COMELLA, Annamaria. Tipologia e diffusione dei complessi votivi in Italia in epoca medio- e tardo-repubblicana. Mélanges de l'École Française de Rome, Antiquité, vol. 93, fasc. 2, Roma: École Française de Rome, 1981, p. 717-803.

${ }^{66}$ GENTILLI, Maria Donatella. Riflessioni sul fenomeno storico dei depositi votivi di tipo etrusco-laziale-campano. In: COMELLA, Annamaria \& MELE, Sebastiana (org.). Depositi votivi e culti dell'Italia antica dall'età arcaica a quella tardo-repubblicana. Bari: Laterza, 2005, p. 367-78.

${ }^{67}$ COMELLA, Annamaria, op. cit.

${ }^{68}$ COMELLA, Annamaria \& MELE, Sebastiana (org.). Depositi votivi e culti dell'Italia antica dall età arcaica a quella tardo-repubblicana. Bari: Laterza, 2005.
} 
santuários e assentamentos itálicos (ver abaixo). ${ }^{69}$ Dado que a disseminação de ex-votos anatômicos de terracotta é em grande medida contemporânea à expansão romana na Itália, muitos estudiosos inicialmente interpretaram tais artefatos como um reflexo direto da conquista romana e até mesmo como instrumentos de um imperialismo cultural romano. ${ }^{70}$

O que mais chama a atenção sobre esse tipo de ex-voto é a ênfase que ele parece colocar na pessoa do adorador, e não na divindade. Parece provável que os membros e órgãos representados por essas peças se referissem às partes do corpo do dedicante (ou de seus entes queridos) que precisavam de cura divina. Desse modo, os ex-votos anatômicos podem ser interpretados como uma expressão mais direta dos problemas pessoais de saúde do dedicante. ${ }^{71}$ Seria até possível falar de uma redefinição da relação humano-divino: os dedicantes estariam afirmando a si próprios, e às suas necessidades pessoais, diante da divindade. Tal mudança parece ter sido de amplíssimo alcance, muito além de uma simples influência cultural romana. Em primeiro lugar, há que se considerar que esses ex-votos, no geral, são tecnicamente muito simples e fáceis de produzir com fôrmas; daí a conclusão, amplamente aceita, de que ex-votos anatômicos eram normalmente dedicados por pessoas comuns, como camponeses de status equivalente à plebe romana. ${ }^{72}$

\footnotetext{
${ }^{69}$ D'ERCOLE, Maria Cecilia. La stipe votiva del Belvedere a Lucera. Corpus delle stipi votive in Italia 3. Roma: G. Bretschneider, 1990.

${ }^{70}$ COARELLI, Filippo. Il Lucus Pisaurensis e la romanizzazione dell'ager Gallicus. In BRUUN, Christer. (org.). The Roman middle Republic. Politics, religion, and historiography, c. 400 - 133 BC. Roma: Instituti Romani Finlandiae, 2000, p. 200; DE CAZANOVE, Olivier. Itinéraires et étapes de l'avancée romaine entre Samnium, Daunie, Lucanie et Etrurie. In: BRIQUEL, Dominique \& THUILLIER, Jean Paul (org.). Le censeur et les Samnites. Sur Tite-Live, livre IX. Paris: Études de littérature ancienne, 2001, p.191.

${ }^{71}$ GLINISTER, Fay. Reconsidering "religious romanization". In: SCHULTZ, Celia E. \& HARVEY, Paul B. (org.). Religion in Republican Italy. Cambridge: Cambridge University Press, 2006, p. 10-33.

${ }^{72}$ Cf. TURFA, Jean Macintosh. Anatomical votives and Italian medical tradition. In: DE PUMA, Richard Daniel \& SMALL, Jocelyn Penny (org.). Murlo and the Etruscans. Madison: University of Wisconsin Press, 1994, p. 224-225; TORELLI, Mario. Tota Italia. Essays in the cultural formation of Roman Italy. Oxford: Oxford University Press, 1999, p. 8-9; Isso não significa, entretanto, que essas peças não pudessem ser dedicadas por pessoas de condição socioeconômica mais elevada: dentre os inúmeros exemplares, encontramos ocasionalmente algumas peças de melhor qualidade, feitas de argila purificada e que exibem trabalho artesanal mais sofisticado, tais como detalhes adicionais modelados à mão. Esses itens mais sofisticados podem ter sido encomendados por compradores mais abastados: cf. POTTER, Timothy $\&$ WELLS, Colin. A Republican healing-sanctuary at Ponte di Nona near Rome and the classical tradition of votive medicine. Journal of the British Association of Archaeologists, vol. 138, Londres: British Archaeological Association, 1985, p. 28-29; GLINISTER, Fay, op. cit., p. 28. É plausível concluir que ex-votos anatômicos de terracota eram dedicados por pessoas de status socioeconômico diverso. A sua
} 
Estaríamos lidando, potencialmente, com uma tendência no comportamento religioso das massas.

É difícil sustentar que Roma foi a origem dessa nova tendência cultural-religiosa. Os mais antigos ex-votos anatômicos que conhecemos vêm não de Roma, mas da Grécia, mais especificamente de Corinto no século VII a. C., e continuam presentes entre as oferendas em vários santuários gregos até o final do período helenístico (séculos IV-II a. C.). Além disso, recentes escavações revelaram que ex-votos anatômicos parecem anteceder as fundações de algumas colônias romanas na Itália. ${ }^{73}$ Em vista disso, parece bastante provável que a prática itálica (e romana) de oferecer ex-votos anatômicos estava de alguma maneira ligada à interação com o mundo grego. ${ }^{74}$ Isso não significa que a disseminação dos ex-votos anatômicos na Itália não teve nada a ver com Roma: a construção da malha viária romana, ligando regiões da península previamente isoladas, intensificou a conectividade, permitindo que a nova tendência religiosa pudesse viajar mais rapidamente até regiões mais remotas ou previamente inacessíveis.

Em um mundo de novas e crescentes conexões globais, comunidades locais ganhavam acesso a novas mercadorias e ideias (como discutido acima em relação à $\mathrm{CVN}$ ). Ao invés de serem passivamente absorvidas, essas tendências globais eram apropriadas e ressignificadas de acordo com disposições culturais locais; o global adquiria um sabor local. ${ }^{75}$ Podemos tomar, como estudo de caso, uma amostragem de 244 ex-votos provenientes de 16 santuários da Itália central, todos frequentados entre os séculos IV e II a. C. (figura 5). Uma segunda amostragem de nove santuários, situados na área tirrênica (Etrúria, Lácio e Campânia) e na Itália meridional (Daunia; cf. figura 5), servirá para fins comparativos. ${ }^{76}$ À primeira vista, os tipos de

maioria teria sido formada por membros das classes populares, que não teriam tido meios para dedicar objetos mais caros. No entanto, oferentes mais ricos teriam sido responsáveis por aqueles ex-votos mais sofisticados e personalizados.

${ }^{73}$ GENTILLI, Maria Donatella, op. cit.; Cf. CAMPANELLI, Adele \& FAUSTOFERRI, Amalia (org.). I luoghi degli dei. Sacro e natura nell'Abruzzo italico. Chieti: Soprintendenza Archeologica dell'Abruzzo, 1997; GLINISTER, F., op. cit.

${ }^{74}$ GLINISTER, Fay, op. cit., p. 17-26, onde a autora observa algumas importantes diferenças entre ex-votos anatômicos na Itália e na Grécia.

${ }^{75}$ APPADURAI, Arjun. Introduction: commodities and the politics of value. In: Idem (org.). The social life of things. Cambridge: Cambridge University Press, 1986, p. 3-63; PITTS, M., op. cit., p. 495.

${ }^{76}$ Tarquinia-Ara della Regina; Gravisca; Pyrgi-Templo A; Veio-Campetti; Veio-Porta Caere (Etrúria meridional); Roma-Minerva Medica; Lavinium (Lácio); Paestum-Santa Venera (Campânia); e Luceria (Daunia). 
ex-votos anatômicos presentes na amostra da Itália central parecem menos variados do que aqueles da Itália tirrênica e meridional: os santuários etruscos e latinos parecem exibir uma diversidade maior de órgãos e membros, muitos dos quais estão ausentes dos santuários da Itália central selecionados para a presente análise (figuras 3 e 4). Além disso, os santuários da Itália central se destacam por conter muitos ex-votos que representam mãos, braços, pés e pernas, enquanto que peças representando órgãos reprodutivos parecem ser menos frequentes (figura 5). Isso contrasta com a situação na área tirrênica (Etrúria, Lácio e Campânia: figura 5): úteros e outros órgãos reprodutivos parecem ser muito mais numerosos nos santuários de Tarquinia-Ara della Regina, Gravisca, Veio (Etrúria) e Paestum-Santa Venera (Campânia), do que em qualquer santuário centro-italiano na presente amostra. Vale também notar que três dos santuários tirrênicos com grandes quantidades de ex-votos representando órgãos reprodutivos (Tarquinia, Gravisca e Paestum) também incluem estatuetas de crianças enfaixadas, que parecem reforçar a ênfase na esfera da fertilidade e reprodução. ${ }^{77}$

Esse quadro geral parece indicar um importante elemento de seleção por parte dos oferentes. Tal como na discussão acima sobre a cerâmica de verniz negro, deparamo-nos com o problema de que a presente amostragem de ex-votos é limitada aos dados arqueológicos publicados. Ainda assim, algumas hipóteses preliminares podem ser formuladas. A aparente escassez, na Itália central, de peças relacionadas a reprodução não parece ter sido uma simples questão de acesso, a julgar pela presença de alguns úteros de terracota nos santuários centro-itálicos, embora em menor número do que na área tirrênica. Também parece pouco provável que as comunidades da Itália central não tivessem recursos para adquirir ex-votos no formato de órgãos reprodutivos, uma vez que, em princípio, esses objetos teriam sido tão fáceis (ou difíceis) de fabricar quanto os ex-votos retratando outros órgãos/ membros do corpo humano. Portanto, podemos considerar a predominância de braços, mãos, pernas e pés na Itália central como um provável indicador de preferências culturais locais. Tais preferências teriam, supostamente, se fundamentado em atitudes religiosas e valores culturais locais, e em noções sobre qual era a relação "adequada" entre humanos e deuses. Essas atitudes e valores, por sua vez, podem ter estado associados a certas convenções culturais sobre o corpo humano, e quais partes desse corpo eram consideradas

${ }_{77}$ COMELLA, Annamaria, op. cit., p. 764-765. 
adequadas para serem representadas ou invocadas em contextos de culto religioso. Em termos da teoria sociológica da agência, ${ }^{78}$ tais predisposições culturais fariam parte da "estrutura" (ou habitus) que definiria a maneira em que as comunidades da Itália central atribuíam sentido aos ex-votos anatômicos. ${ }^{79}$

Há indícios de que tais predisposições culturais eram de longa data. Desde a Idade do Ferro, santuários na Itália central já parecem se destacar pela ausência de artefatos relacionados a reprodução e fertilidade. Ao contrário, muitos santuários centro-itálicos incluíam figuras representando pés, pernas e mãos, embora tais peças mais antigas sejam feitas de bronze ao invés de terracota. ${ }^{80}$ É muito difícil datar esses bronzes com precisão, devido à falta de dados estratigráficos. No entanto, dois pontos são mais ou menos claros: i) os bronzes anatômicos sugerem que a dedicação de ex-votos retratando partes do corpo já era praticada na Itália central antes da conquista romana no século IV a. C.;1 ii) o fato dessas peças mais antigas de bronze retratarem pés, pernas, mãos, ao invés de órgãos reprodutivos, é consistente com o padrão verificado na presente amostragem da Itália central a partir do século IV a. C.

Como interpretar o aparente desinteresse em ex-votos referentes a fertilidade e reprodução na Itália central? Primeiramente, não devemos supor que as comunidades em questão não se preocupavam com questões de reprodução: tais preocupações podem simplesmente ter sido expressas em contextos menos públicos. Ao mesmo tempo, os vários ex-votos retratando pés e mãos podem indicar certas preocupações com o corpo, consideradas mais adequadas para o contexto público do santuário. Possivelmente, os numerosos pés e pernas de terracota seriam indícios de problemas de saúde que normalmente afetam trabalhadores agrícolas, como a artrite. ${ }^{82}$ Entretanto, pés e pernas também podem ter simbolizado o ato de viajar, ou

\footnotetext{
${ }^{78}$ GARDNER, Andrew (org.). Agency uncovered. Archaeological perspectives on social agency, power and being human. Walnut Creek: Left Coast Press, 2004, p. 3-5.

${ }^{79}$ Habitus: BOURDIEU, Pierre. Outline of a theory of practice. Cambridge: Cambridge University Press, 1977.

${ }^{80}$ Cf. MONACCHI, Daniela. I resti della stipe votiva del Monte Subasio di Assisi (Colle S. Rufino). Studi Etruschi, vol. 52, Florença: Istituto Nazionale di Studi Etruschi ed Italici, 1984, p. 77-89; MONACCHI, Daniela. Nota sulla stipe votiva di Grotta Bella. Studi Etruschi, vol. 54, Florença: Istituto Nazionale di Studi Etruschi ed Italici, 1986, p. 75-99; BRADLEY, Guy. Ancient Umbria. State, culture and identity in central Italy from the Iron Age to the Augustan era. Oxford: Oxford University Press, 2000, p.176.

${ }^{81}$ GLINISTER, Fay, op. cit., p. 14.

${ }^{82}$ POTTER, Timothy $\mathcal{E}$ WELLS, Colin, op. cit., p. 42.
} 
outras atividades cotidianas que envolvessem caminhar longas distâncias. ${ }^{83}$ Pés também poderiam simbolizar peregrinação e peregrinos; ${ }^{84} \mathrm{em}$ um nível mais abstrato, poderiam funcionar como imagens de apoio e estabilidade. Mãos, por sua vez, poderiam representar o ato de orar, ou remeter à esfera do trabalho manual, produção, e artesanato.

É importante ressaltar que a aparente preferência centro-italiana por mãos, pernas e pés não é um fenômeno completamente regional. Pode-se observar algo semelhante em certos santuários latinos incluídos na presente amostra (Roma-Minerva Medica e Lavinium: figura 5), bem como na Grécia continental durante o período helenístico (300-150 a. C.). Mãos, braços, pés e pernas de terracota estão entre os mais numerosos ex-votos no santuário de Asclépio em Corinto. ${ }^{85}$ No entanto, pés, pernas, braços e mãos são muito menos numerosos nos santuários da Magna Grécia - os quais, ao contrário, assemelham-se mais aos santuários etruscos e campanos no que diz respeito à ênfase na fertilidade. ${ }^{86}$ Aparentemente, as disposições culturais na Itália central estavam em sintonia com a Grécia continental, talvez mais que com regiões vizinhas como Etrúria e Magna Grécia.

\section{Conclusões}

Este artigo pretendeu demonstrar o potencial analítico do conceito de globalização, tal como discutido recentemente na história global, para o estudo do impacto da hegemonia romana nascente (séculos IV-II a. C.), como alternativa a conceitos tradicionais de romanização e helenização. Ao explorar a formação de conexões globais no Mediterrâneo sob a nascente hegemonia romana, os estudos de caso acima nos oferecem pontos de partida para reflexões sobre a conectividade e seu impacto.

O primeiro estudo de caso - sobre o boom do vinho grego na Itália após a segunda Guerra Púnica - já revela algumas limitações de modelos hierár-

\footnotetext{
${ }^{85}$ Pés de terracota eram também depositados ao longo das rotas de transumância na Itália central: ANTONACCI SANPAOLO, Elena. Sannio e Apulia: acculturazioni e commerci. In: CAPELLI, Rosanna (org.). Studi sull'Italia dei Sanniti. Milão: Electa, 2000, p. 90-106.

${ }^{84}$ GLINISTER, Fay, op. cit., p. 12.

${ }^{85}$ ROEBUCK, Carl. Corinth XIV: The Asklepeion and Lerna. Princeton: Princeton University Press, 1951, p. 114, 125-128.

${ }^{86}$ AMMERMAN, Rebecca. The Sanctuary of Santa Venera at Paestum II: the votive terracottas. Ann Arbor: University of Michigan Press, 2002, p. 322-323.
} 
quicos e territorialmente fixos, de tipo "centro-periferia". ${ }^{87}$ Apesar da Itália ser o centro político da nova hegemonia romana sobre o mundo grego, a conectividade entre as duas regiões atravessava, e de certa forma subvertia, a hierarquia geopolítica. Do ponto de vista cultural, pode-se dizer que Rodes (e o mundo helenístico em geral) tornou-se um importante "centro" de referência daquilo que as elites romanas e itálicas consideravam comportamento refinado. Em outras palavras, o mundo helenístico passou a ser um parâmetro central, em relação ao qual romanos e itálicos buscavam validar as suas credenciais culturais.

Por outro lado, os estudos de caso também revelam que a globalização resultante da expansão romana gerou novas formas de desigualdade. Toda globalização tem seus vencedores e perdedores, aqueles que se veem mais ou menos beneficiados pelas redes de contato e de mobilidade. ${ }^{88}$ Não basta falar em conectividade aumentada: é também necessário examinar quais conectividades se formam e entre quem, quais tráfegos ou fluxos se intensificam e quais enfraquecem, quem sai ganhando e quem perde. Se Rodes não tivesse sido um aliado tão importante na conquista romana da Grécia, talvez não teria sido o vinho ródio a invadir a Itália.

Já as discussões sobre cerâmica de verniz negro e ex-votos anatômicos oferecem perspectivas importantes acerca do processo de "universalização do particular e particularização do universal" - ou seja, sobre como conexões globais disseminam novas tendências culturais e como essas tendências assumem um caráter distinto ao entrar em contato com tradições e culturas locais. O paradigma da glocalização tem enorme potencial analítico para o estudo das transformações culturais estimuladas com o início da expansão romana. ${ }^{89}$ Como demonstrado acima, a disseminação da cerâmica de verniz negro e dos ex-votos anatômicos informam-nos sobre fenômenos glocalizantes também entre grupos sociais que não exclusivamente as elites. Ex-votos anatômicos tendiam a enfatizar a pessoa do adorador humano na relação humano-divino: isso representou uma mudança importante em relação às práticas anteriores, quando a ênfase parecia ser colocada nos próprios deuses e na necessidade de agradá-los com presentes. O que mais nos interessa, entretanto, é o fato de que as comunidades itálicas que aderiram

\footnotetext{
${ }^{87}$ Cf. CONRAD, Sebastian, op. cit., p. 117-18 (sobre a busca por "espaços históricos alternativos").

${ }^{88}$ CONRAD, Sebastian, op. cit., p. 213; MORRIS, Ian, op. cit., p. 46-51.

${ }^{89}$ Sobre a glocalização no Mediterrâneo antigo (período arcaico), cf. VLASSOPOULOS, Kostas, op. cit., p. 140-46.
} 
à moda dos ex-votos anatômicos de terracota fizeram-no de forma bastante seletiva. Em muitos casos, essas comunidades parecem ter inserido os exvotos dentro das suas próprias tradições culturais referentes ao sagrado e ao divino. A relativa escassez, nos santuários centro-itálicos, de peças que retratam órgãos reprodutivos e seios, e o grande número de peças representando mãos, pés e pernas, indicam um certo grau de continuidade das práticas de culto locais. Essas comunidades estavam negociando ativamente um lugar para elas próprias no âmbito de tendências globais, apropriandose de um novo tipo de cultura material religiosa (os ex-votos anatômicos de terracota) e adaptando-a aos os seus próprios valores, crenças e tabus. Ao fim, os ex-votos anatômicos de terracota faziam parte de uma tendência cultural mais ampla, que envolveu não apenas Roma e o Lácio, mas também o mundo grego.

Em nenhum dos estudos de caso acima parece inteiramente adequado falar de helenização ou romanização; ambos esses conceitos apresentam insuficiências e defasagens. Vale a pena considerarmos o potencial das perspectivas da história global, e do conceito de globalização, como novas ferramentas teóricas para o estudo das mudanças socioculturais durante o início da expansão romana. ${ }^{90}$

${ }_{90}^{90}$ PITTS, M. E. J. \& VERSLUYS, M. J., op. cit. 


\section{Figura 1}

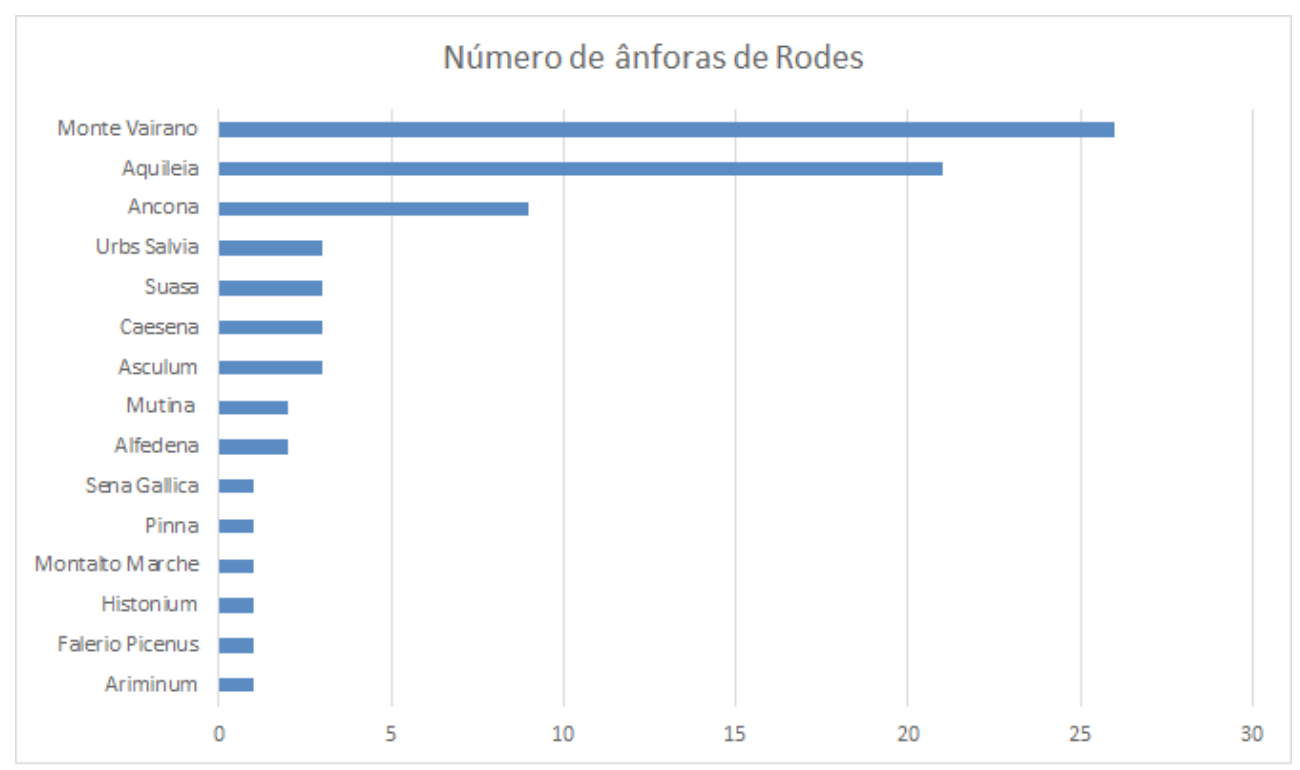

Ânforas ródias na Itália central/adriática

(fonte: MARENGO, S. M. \& PACI, G., 2008)

\section{Figura 2}

\begin{tabular}{|c|c|c|c|c|c|c|c|c|c|}
\hline & Tachos & Ânforas & Crateras & Jarras & Tigelas & Taças & $\begin{array}{c}\text { Outros } \\
\text { recipientes } \\
\text { para beber }\end{array}$ & Pratos & Morteiros \\
\hline $\mathrm{CVN}$ & 5 & 1 & 1 & 10 & 5 & 51 & 12 & 8 & 1 \\
\hline $\begin{array}{c}\text { Cerâmica } \\
\text { comum/ } \\
\text { impasto }\end{array}$ & 22 & 4 & 1 & 9 & 12 & 16 & 1 & 0 & 0 \\
\hline
\end{tabular}

Amostragem de recipientes de cerâmica do Samnium, séculos III-II a. C. 


\section{Figura 3}

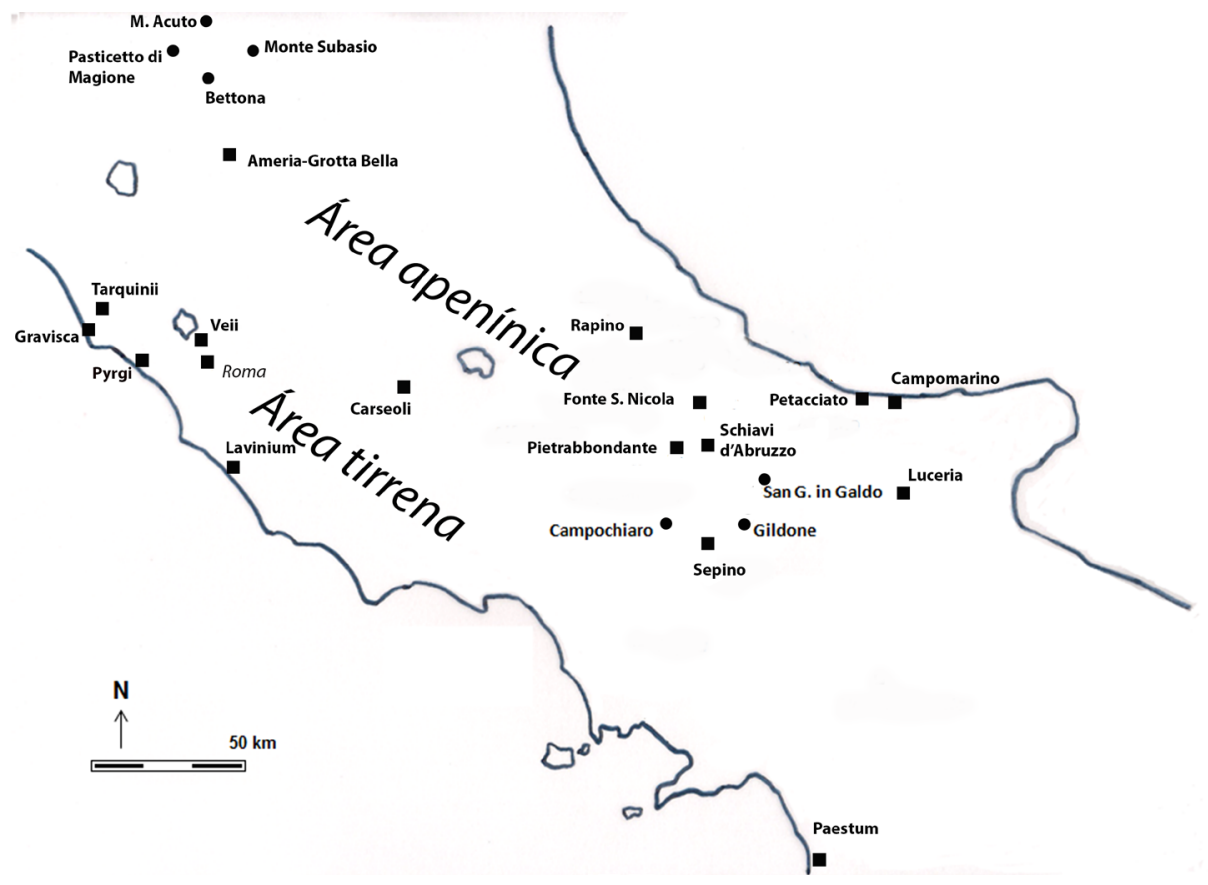

Santuários na Itália centro-meridional, séculos IV-II a. C.

Figura 4

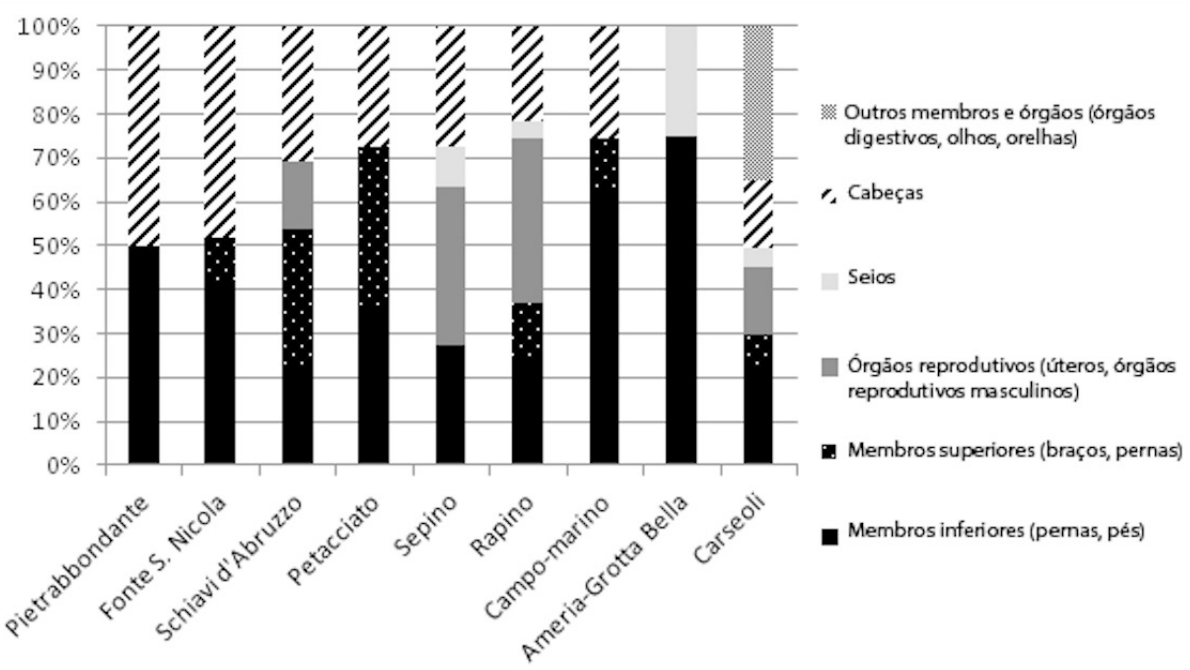

Tipos de ex-votos anatômicos em santuários da Itália central (fonte: SCOPACASA, Rafael. Moldando mudança cultural: uma abordagem contextual aos ex-votos anatômicos na Itália republicana. Phoînix. Rio de Janeiro, vol. 21, n.1, p. 102-125, 2015.) 


\section{Figura 5}

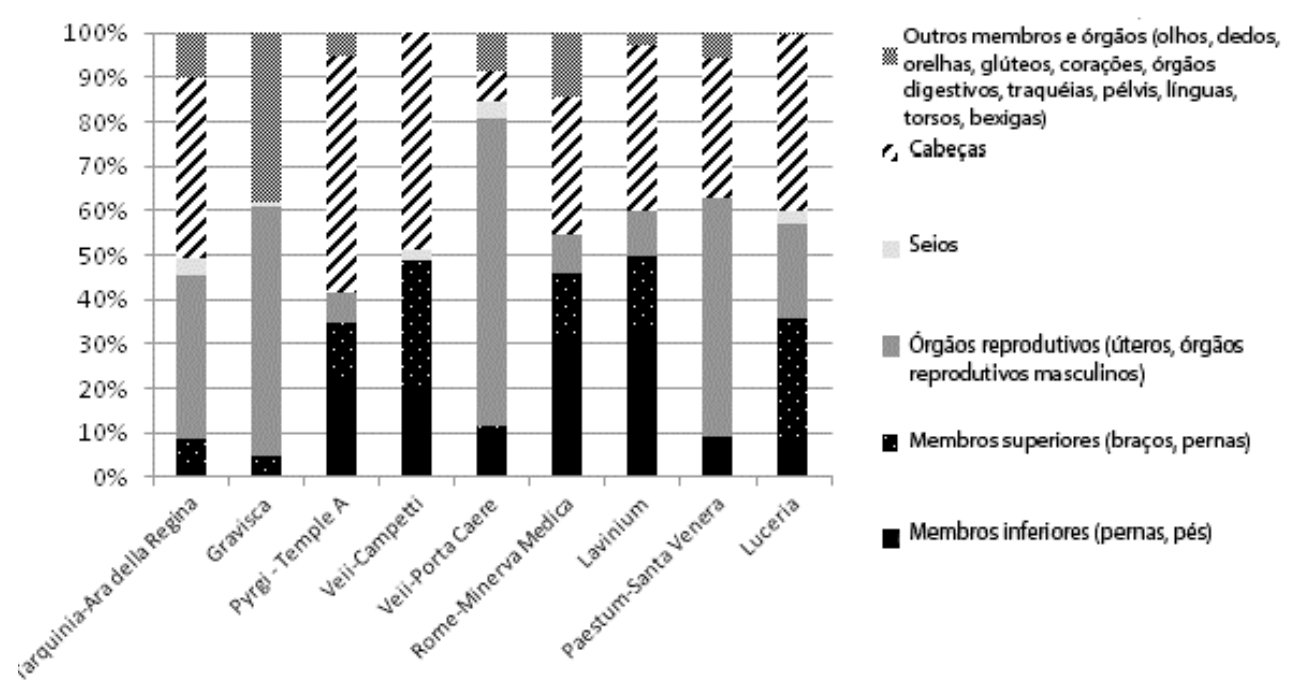

Tipos de ex-votos anatômicos em santuários na Etrúria, Lácio e Daunia (fonte: SCOPACASA, Rafael. Moldando mudança cultural: uma abordagem contextual aos ex-votos anatômicos na Itália republicana. Phoînix. Rio de Janeiro, vol. 21, n.1, p. 102-125, 2015.) 


\section{Referências bibliográficas}

\section{Fontes primárias}

Lívio. Livy. Ab urbe condita, livros 1-10. Londres: Heinemann, 1919-1929. Ab urbe condita, livros 23-30. Londres: Heinemann, 1940-1949. . Ab urbe condita, livros 31-39. Londres: Heinemann, 1935-1936. . Ab urbe condita, Summaries, fragments and obsequens, livros 40-45. Londres: Heinemann, 1938-1959.

Políbio. Polybius. Histories. Cambridge Mass.: Harvard University Press, 2010.

Zonaras. Dio Cassius. Roman history, vol. I. Cambridge Mass.: Harvard University Press, 1925.

\section{Bibliografia}

AMMERMAN, Rebecca. The Sanctuary of Santa Venera at Paestum II: the votive terracottas. Ann Arbor: University of Michigan Press, 2002.

ANTONACCI SANPAOLO, Elena. Sannio e Apulia: acculturazioni e commerci. In: CAPELLI, R. (org.). Studi sull'Italia dei Sanniti. Milão: Electa, 2000, p. 90-106.

APPADURAI, Arjun. Introduction: commodities and the politics of value. In: Idem (org.). The social life of things. Cambridge: Cambridge University Press, 1986, p. 3-63. . Grassroots globalization and the research imagination. In: Idem (org.). Globalization. Durham: Duke University Press, 2001.

BELICH, James; DARWIN, John; WICKHAM, Christopher. Introduction. In: BELICH, James; DARWIN, John; FRENZ, Margret; WICKHAM, Christopher (org.). The prospect of global history. Oxford: Oxford University Press, 2016, p. 3-22.

BISPHAM, Edward. From asculum to actium. The municipalisation of Italy from the social war to Augustus. Oxford: Oxford University Press, 2007.

BOURDIEU, Pierre. Outline of a theory of practice. Cambridge: Cambridge University Press, 1977.

BRADLEY, Guy. Ancient Umbria. State, culture and identity in central Italy from the Iron Age to the Augustan era. Oxford: Oxford University Press, 2000.

BROODBANK, Cyprian. The making of the middle sea. Londres: Thames and Hudson, 2013.

BURTON, Paul. Friendship and empire. Roman diplomacy and imperialism in the middle Republic (353-146 BC). Cambridge: Cambridge University Press, 2011.

CAMPANELLI, Adele $\mathcal{E}$ FAUSTOFERRI, Amalia (org.). I luoghi degli dei. Sacro e natura nell'Abruzzo italico. Chieti: Soprintendenza Archeologica dell'Abruzzo, 1997.

CAPINI, Stefania. 1980. Il santuario di Ercole a Campochiaro. In Sannio. Pentri e Frentani dal VI al I sec. a. C. Roma: De Luca, 1980, p. 197-217.

CLARKE, David B. The consumer society and the postmodern city. Londres: Routledge, 2003.

COARELLI, Filippo. Il Lucus Pisaurensis e la romanizzazione dell'ager Gallicus. In: BRUUN, Christer (org.). The Roman middle Republic. Politics, religion, and historiography, c. 400-133 BC. Roma: Instituti Romani Finlandiae, 2000, p. 195-205. 
COMELLA, Annamaria. Tipologia e diffusione dei complessi votivi in Itália in epoca medio- e tardo- reppublicana. Mélanges de l'École Française de Rome, Antiquité, vol. 93, fasc. 2, Roma: École Française de Rome, 1981, p. 717-803.

COMELLA, Annamaria \& MELE, Sebastiana (org.). Depositi votivi e culti dell'Italia antica dall età arcaica a quella tardo-repubblicana. Bari: Laterza, 2005.

CONRAD, Sebastian. What is global history? Princeton: Princeton University Press, 2016.

CORNELL, Timothy J. The conquest of Italy. In: WALBANK, Frank W.; ASTIN, Alan E.; FREDERIKSEN, Martin W.; OGILVIE, Robert M. (org.). Cambridge Ancient History, vol. 7.2. Cambridge: Cambridge University Press, 1989, p. 351-419.

CROSSLEY, Pamela. What is global history. Cambridge: Polity Press, 2008.

DE CAZANOVE, Olivier. Itinéraires et étapes de l'avancée romaine entre Samnium, Daunie, Lucanie et Etrurie. In: BRIQUEL, Dominique $\mathcal{E}$ THUILLIER, Jean Paul (org.). Le censeur et les Samnites. Sur Tite-Live, livre IX. Paris: Études de littérature ancienne, 2001, p. 147-192.

DE BENEDITTIS, Gianfranco. L'abitato di Monte Vairano ovvero Aquilonia. In: Sannio: Pentri e Frentani dal VI al I secolo a. C. Roma: De Luca, 1980, p. 321-341.

DE BENEDITTIS, Gianfranco \& BEVILACQUA, Gabriella. Le anfore, Bolli Rodi. In: Sannio: Pentri e Frentani dal VI al I secolo a. C. Roma: De Luca, 1980, p. 306-8, 342-8.

DE BENEDITTIS, Gianfranco. Monte Vairano: La casa di LN. Catalogo della mostra. Campobasso: Studio Emmezeta, 1988.

DENCH, Emma. From Barbarians to new men: Greek, Roman, and modern perceptions of the Central Apennines. Oxford: Clarendon, 1995.

DI NIRO, Angela. Larino: la città elenistica e romana. In: Sannio: Pentri e Frentani dal VI al I sec. a. C. Roma: De Luca, 1980, p. 286-306.

Necropoli arcaiche di Termoli e Larino. Campagne di scavo 1977-78. Campobasso. Soprintendenza archeologica e per i beni architettonici artistici e storici del Molise, 1981.

Guglionesi. Necropoli arcaica. Conoscenze, vol. 3, Campobasso: Soprintendenza Archeologica del Molise, 1986, p. 153-64.

Il sepolcreto sannitico di Gildone. Conoscenze, vol. 5, Campobasso: Soprintendenza Archeologica del Molise, 1989, p. 27-36.

Cercemaggiore-Gildone: la Casa, le Tombe e il Sacello. In: CAPINI, Stefania \& DI NIRO, Angela (orgs.). Samnium: Archeologia del Molise. Roma: Quasar, 1991, p. 121-26.

. La zona frentana tra IV e I sec. a. C. In: CAPINI, Stefania $\mathcal{E}$ DI NIRO, Angela (org.). Samnium. Archeologia del Molise. Roma: Quasar, 1991, p. 131-134.

D'ERCOLE, Maria Cecilia. La stipe votiva del Belvedere a Lucera. Corpus delle stipi votive in Italia 3. Roma: G. Bretschneider, 1990.

ECKSTEIN, Arthur M. Mediterranean anarchy, interstate war and the rise of Rome. Berkeley: University of California Press, 2006.

Rome enters the Greek East. From anarchy to hierarchy in the Eastern Mediterranean. Oxford: Blackwell, 2012. 
FAUSTOFERRI, Amalia. L'area sacra di Fonte San Nicola: i votivi. In: CAMPANELLI, Adele $\mathcal{E}$ FAUSTOFERRI, Amalia (orgs.). I luoghi degli dei. Sacro e natura nell'Abruzzo italico. Chieti. Soprintendenza Archeologica dell'Abruzzo, 1997, p. 99-109.

FLOWER, Harriet. The dancing Lares and the serpent in the garden: religion at the Roman street corner. Princeton: Princeton University Press, 2017.

FRONDA, Michael. Between Rome and Carthage. Southern Italy during the Second Punic War. Cambridge: Cambridge University Press, 2010.

GARDNER, Andrew (org.). Agency uncovered. Archaeological perspectives on social agency, power and being human. Walnut Creek: Left Coast Press, 2004.

GENTILLI, Maria Donatella. Riflessioni sul fenomeno storico dei depositi votivi di tipo etrusco-laziale-campano. In: COMELLA, Annamaria $\mathcal{E}$ MELE, Sebastiana (org.). Depositi votivi e culti dell'Italia antica dall'età arcaica a quella tardo-repubblicana. Bari: Laterza, 2005, p. 367-78.

GIDDENS, Anthony. The consequences of modernity. Stanford: Stanford University Press, 1990.

GLINISTER, Fay. Reconsidering "religious romanization". In: SCHULTZ, Celia E. $\mathcal{E}$ HARVEY, Paul B. (org.). Religion in Republican Italy. Cambridge: Cambridge University Press, 2006, p. 10-33.

GUARINELLO, Norberto Luiz. Ordem, integração e fronteiras no Império romano: um ensaio. Mare Nostrum, vol. 1, São Paulo, 2010, p. 113-127.

HARRIS, William V. Rome in Etruria and Umbria. Oxford: Clarendon, 1971.

. Volsinii and Rome, 400-100 BC. Volsinii e la dodecapoli etrusca. Annali della fondazione per il Museo "Claudio Faina", vol. 2, Orvieto: Museo Claudio Faina, 1985, p. 143-56.

. The Mediterranean and ancient history. In: Idem (org.). Rethinking the Mediterranean. Oxford: Oxford University Press, 2005, p. 1-42.

HARVEY, David. The condition of postmodernity. Oxford: Blackwell, 1989.

HORDEN, Peregrine. Introduction. In: HORDEN, Peregrine $\mathcal{E}$ KINOSHITA, Sharon (org.). A companion to Mediterranean history. Oxford: Wiley Blackwell, 2014, p. 1-7.

HORDEN, Peregrine \& PURCELL, Nicholas. The corrupting sea: a study of Mediterranean history. Oxford: Blackwell, 2000.

KANE, Susan. Life "on the edge": a view from the Abruzzo. In: LOCK, Gary \& FAUSTOFERRI, Amalia (org.). Archaeology and landscape in Central Italy: papers in memory of John A. Lloyd. Oxford: School of Archaeology, 2008, p. 93-103. (Oxford University School of Archaeology: Monographs 69)

KEAY, Simon $\mathcal{E}$ TERRENATO, Nicola (org.). Italy and the West. Comparative issues in romanization. Oxford: Oxbow, 2011.

KLEINBERG, Ethan $\&$ PINCH. William E. History and theory in a global frame. History and Theory, vol. 54, n. 4, Middletown, 2015, p. 1-4.

LAPENNA, Sandra. La stipe votiva di Schiavi. In: CAMPANELLI, Adele $\mathcal{E}$ FAUSTOFERRI, Amalia (orgs.). I luoghi degli dei. Sacro e natura nell'Abruzzo italico. Chieti, Soprintendenza Archeologica dell'Abruzzo, 1997, p. 117-26. 
LA REGINA, Adriano. Il Sannio. In: ZANKER, Paul (org.). Hellenismus in Mittelitalien. Kolloquium in Göttingen vom 5 bis 9 Juni 1974. Gottingen: Vanderhoeck und Ruprecht, 1976, p. 219-44.

MACCHIAROLA, Ida. I corredi del sepolcreto di Gildone. Conoscenze, vol. 5, Campobasso: Soprintendenza Archeologica del Molise, 1989, p. 37-79.

MARENGO, Silvia M. \& PACI, Gianfranco. Per la circolazione delle anfore rodie e tardo-repubblicane in area adriatica. In: BUONOPANE, Alfredo (org.). Est enim ille flos Italiae. Vita economica e sociale nella Cisalpina romana. Verona, 2008, p. 313-28.

MATTINGLY, David John. Dialogues of power and experience in the Roman Empire. In: idem (org.). Dialogues in Roman imperialism. Power, discourse and discrepant experience in the Roman Empire. Portsmouth, RI: Journal of Roman Archaeology, 1997, p. 7-24.

Being Roman: expressing identity in a provincial setting. Journal of Roman Archaeology, vol. 17, Portsmouth, RI: Journal of Roman Archaeology, 2004, p. 5-25.

Imperialism, power and identity. Experiencing the Roman Empire. Princeton: Princeton University Press, 2011.

MONACCHI, D. I resti della stipe votiva del Monte Subasio di Assisi (Colle S. Rufino). Studi Etruschi, vol. 52, Florença: Istituto Nazionale di Studi Etruschi ed Italici, 1984, p. 77-89.

Nota sulla stipe votiva di Grotta Bella. Studi Etruschi, vol. 54, Florença: Istituto Nazionale di Studi Etruschi ed Italici, 1986, p. 75-99.

MOREL, Jean Paul. The transformation of Italy, 300-133 BC: the evidence of archaeology. In: Cambridge Ancient History, vol. VIII. Cambridge: Cambridge University Press, 1989, p. 477-516.

MORELLI, Alexandre. Perspectivas globais e transnacionais: vida (e morte?) da história global. Estudos Históricos, vol. 30, n. 60, Rio de Janeiro, 2017, p. 5-16.

MORRIS, Ian. Mediterraneanization. The Mediterranean Historical Review, vol. 18, n. 2, Londres, 2005, p. 30-55.

OLSTEIN, Daniel. Thinking history globally. Basingstoke: Palgrave Macmillan, 2014.

PARISE BADONI, Franca $\mathcal{E}$ RUGGIERI GIOVE, Maria. Alfedena, la necropoli di Campo Consolino: scavi, 1974-1979. Chieti: Soprintendenza Archeologica dell'Abruzzo, 1981.

PITTS, Martin E. J. Globalising the local in Roman Britain: an anthropological approach to social change. Journal of Anthropological Archaeology, vol. 27, fasc. 4, Albuquerque: Elsevier, 2008, p. 493-506.

PITTS, Martin E. J. \& VAN OYEN, Astrid. What did objects do in the Roman world? Beyond representation. In: Idem (org.). Materialising Roman histories. Oxford: Oxbow Books, 2017, p. 3-20.

PITTS, Martin E. J. E VERSLUYS, Miguel John (org.). Globalisation and the Roman world: world history, connectivity and material culture. Cambridge: Cambridge University Press, 2014.

POTTER, Timothy W. \& WELLS, Colin. A Republican healing-sanctuary at Ponte di Nona near Rome and the classical tradition of votive medicine. Journal of the British Association of Archaeologists, vol. 138, Londres: British Archaeological Association, 1985, p. 23-47. 
PURCELL, Nicholas. Unnecessary dependences: illustrating circulation in pre-Modern large-scale history. In: BELICH, James; DARWIN, John; FRENZ, Margret; WICKHAM, Christopher. (org.). The prospect of global history. Oxford: Oxford University Press, 2016, p. 65-79.

RAININI, Ivan. Capracotta: l'abitato sannitico di Fonte del Romito. Roma: Quasar, 1996.

RASMUSSEN, Tom \& SPIVEY, Nigel. Looking at Greek vases. Cambridge: Cambridge University Press, 1991.

RICH, John W. Treaties, allies and the Roman conquest of Italy. In: DE SOUZA, Philip \& FRANCE, John (org.). War and peace in ancient and medieval history. Cambridge: Cambridge University Press, 2008, p. 51-75.

ROBERTSON, Roland. Globalization. Social theory and global culture. Londres: Sage, 1992.

ROEBUCK, Carl. Corinth XIV: The Asklepeion and Lerna. Princeton: Princeton University Press, 1951.

ROSELAAR, Saskia Tessa. Public land in the Roman Republic: a social and economic history of ager publicus in Italy, 396-89 BC. Oxford: Oxford University Press, 2010.

Introduction. Integration and identity in the Roman Republic. In: Idem (org.). Processes of integration and identity formation in the Roman Republic. Leiden: Brill, 2012, p. 1-16.

Mediterranean trade as a process of integration between Romans and Italians. In: Idem (org.). Processes of integration and identity formation in the Roman Republic. Leiden: Brill, 2012, p. 141-158.

ROSELAAR, Saskia Tessa (org.). Processes of integration and identity formation in the Roman Republic. Leiden: Brill, 2012.

ROTH, Roman. Styling romanisation: pottery and society in Central Italy. Cambridge: Cambridge University Press, 2007.

Before sigillata: black-gloss pottery and its cultural dimensions. In: EVANS, Jane De Rose (org.). A companion to the archaeology of Republican Italy. Oxford: Wiley-Blackwell, 2013, p. 81-96.

Sannio. Pentri e Frentani dal VI al I sec. a. C. Roma: De Luca, 1980.

SCOPACASA, Rafael. Gender and ritual in ancient Italy: a quantitative approach to grave goods and skeletal evidence in pre-Roman Samnium. American Journal of Archaeology, vol. 118, fasc. 2, Boston: The Archaeological Institute of America, 2014, p. 241-66. Ancient Samnium: settlement, culture and identity between history and archaeology. Oxford: Oxford University Press, 2015.

Moldando mudança cultural: uma abordagem contextual aos exvotos anatômicos na Itália republicana. Phoînix. Rio de Janeiro, vol. 21, n. 1, p. 102-125, 2015.

Repensando a romanização: a expansão romana na Itália a partir das fontes historiográficas. Revista de História (USP), vol. 172, São Paulo: Universidade de São Paulo, p. 113-161, 2015.

Old habits die hard: Samnites, Rome, and the perception of international relations in Republican Italy, c. 350-200 BC. Historia: Zeitschrift für Alte Geschichte (no prelo). 
SERRATI, John. Neptune's altars: the treaties between Rome and Carthage (509-226 BC). Classical Quarterly, vol. 56, Cambridge: Cambridge University Press, 2006, p. 113-134.

SPARKES, Brian A. $\mathcal{E}$ TALCOTT, Lucy. Black and plain pottery of the 6th, 5th and 4 th centuries BC. Princeton N. J.: American School of Classical Studies at Athens, 1970.

STEK, Tesse D. Cult places and cultural change in Republican Italy. A contextual approach to religious aspects of rural society after the Roman conquest. Amsterdam: University of Amsterdam Press, 2009.

TAGLiamonTe, Gianluca. I Sanniti. Caudini, Irpini, Pentri, Carricini, Frentani. Milão: Longanesi, 1996.

TERRENATO, Nicola. Tam firmum municipium: The romanization of Volaterrae and its cultural implications. Journal of Roman Studies, vol. 88, Londres: Society for the Promotion of Roman Studies, 1998, p. 94-114.

A tale of three cities. In: KEAY, Simon $\mathcal{E}$ TERRENATO, Nicola (org.). Italy and the West. Comparative issues in romanization. Oxford: Oxbow, 2001, p. 54-67.

The clans and the peasants. Reflections on social structure and change in Hellenistic central Italy. In: VAN DOMMELEN, Peter $\mathcal{E}$ TERRENATO, Nicola (org.). Articulating local cultures. Power and identity under the expanding Roman Republic. Portsmouth RI: The Journal of Roman Archaeology, 2007, p. 13-22.

TOMLINSON, John. Globalization and culture. Cambridge: Polity Press, 1999.

TORELLI, Mario. Tota Italia. Essays in the cultural formation of Roman Italy. Oxford: Oxford University Press, 1999.

TURFA, Jean MacIntosh Anatomical votives and Italian medical tradition. In: DE PUMA, Richard Daniel \& SMALL, Jocelyn Penny (org.). Murlo and the Etruscans. Madison: University of Wisconsin Press, 1994, p. 224-240.

VAN DOMMELEN, Peter. Cultural imaginings. Punic tradition and local identity in Roman Republican Sardinia. In: KEAY, Simon \& TERRENATO, Nicola (org.). Italy and the West. Comparative issues in romanization. Oxford: Oxbow, 2001, p. 68-84.

VLASSOPOULOS, Kostas. Greeks and Barbarians. Cambridge: Cambridge University Press, 2013, p. 230-40.

WALLACE-HADRILL, Andrew. Rome's cultural revolution. Cambridge: Cambridge University Press, 2008.

WATERS, Malcolm. Globalization. Londres: Routledge, 2001.

WEBSTER, Jane \& COOPER, Nick (org.). Roman imperialism: post-colonial perspectives. Leicester: University of Leicester Press, 1996

WITCHER, Robert. Globalisation and Roman imperialism. In: HERRING, Edward \& LOMAS, Katherine (org.). The emergence of state identities in Italy in the first millennium BC. Londres: Accordia Research Institute, 2000.

WOOLF, Greg. Becoming Roman: the origins of provincial civilisation in Gaul. Cambridge: Cambridge University Press, 1998. 